Royal Netherlands Institute for Sea Research

This is a postprint of:

Hummel, H., Avesaath, P. van, Wijnhoven, S., Kleine Schaars, L. et al. (2016). Geographic patterns of biodiversity in European coastal marine benthos. Journal of the Marine Biological Association of the United Kingdom, 97, 507-523

Published version: dx.doi.org/10.1017/S0025315416001119

Link NIOZ Repository: www.vliz.be/nl/imis?module=ref\&refid=261466

Article begins on next page]

The NIOZ Repository gives free access to the digital collection of the work of the Royal Netherlands Institute for Sea Research. This archive is managed according to the principles of the Open Access Movement, and the Open Archive Initiative. Each publication should be cited to its original source - please use the reference as presented.

When using parts of, or whole publications in your own work, permission from the author(s) or copyright holder(s) is always needed. 
Running head: Geographic patterns of benthic diversity in Europe

JMBA-01-16-SIEMBS15-0011

\section{Geographic patterns of biodiversity in European coastal marine benthos}

Herman Hummel ${ }^{1 *}$, Pim van Avesaath ${ }^{1}$, Sander Wijnhoven ${ }^{1,27}$, Loran Kleine-Schaars ${ }^{1}$, Steven Degraer ${ }^{2}$, Francis Kerckhof ${ }^{2}$, Natalia Bojanic ${ }^{3}$, Sanda Skejic $^{3}$, Olja Vidjak³ ${ }^{3}$ Maria Rousou ${ }^{4}$, Helen Orav-Kotta ${ }^{5}$, Jonne Kotta $^{5}$, Jérôme Jourde ${ }^{6}$, Maria Luiza Pedrotti ${ }^{7}$, Jean-Charles Leclerc ${ }^{8}$, Nathalie Simon ${ }^{8}$, Fabienne RigautJalabert ${ }^{8}$, Guy Bachelet ${ }^{9}$, Nicolas Lavesque ${ }^{9}$, Christos Arvanitidis $^{10}$, Christina Pavloudi $^{10}$, Sarah Faulwetter ${ }^{10}$, Tasman Crowe $^{11}$, Jennifer Coughlan ${ }^{11}$, Lisandro Benedetti-Cecchi ${ }^{12}$, Martina Dal Bello ${ }^{12}$, Paolo Magni ${ }^{13}$, Serena Como ${ }^{13}$, Stefania Coppa ${ }^{13}$, Anda Ikauniece ${ }^{14}$, Tomas Ruginis ${ }^{15}$, Emilia Jankowska ${ }^{16}$, Jan Marcin Weslawski $^{16}$, Jan Warzocha ${ }^{17}$, Sławomira Gromisz ${ }^{17}$, Bartosz Witalis ${ }^{17}$, Teresa Silva ${ }^{18}$, Pedro Ribeiro ${ }^{19}$, Valentina Kirienko Fernandes de Matos ${ }^{19}$, Isabel Sousa-Pinto ${ }^{20}$, Puri Veiga ${ }^{20}$, Jesús Troncoso ${ }^{21}$, Xabier Guinda ${ }^{22}$, Jose Antonio Juanes de la Pena ${ }^{22}$, Araceli Puente ${ }^{22}$, Free Espinosa ${ }^{23}$, Angel Pérez-Ruzafa ${ }^{24}$, Matt Frost $^{25}$, Caroline Louise McNeill ${ }^{25}$, Ohad Peleg ${ }^{26}$, Gil Rilov ${ }^{26}$

1) Monitor Taskforce, Royal Netherlands Institute for Sea Research (NIOZ), Yerseke, the Netherlands, ${ }^{2)}$ Royal Belgian Institute of Natural Sciences, OD Nature, Marine Ecology and Management, Brussels and Oostende, Belgium, ${ }^{3)}$ Institute of Oceanography and Fisheries, Split, Croatia, ${ }^{4)}$ Marine \& Environmental Research Lab Ltd, Limassol, Cyprus, ${ }^{5)}$ Estonian Marine Institute, University of Tartu, Tallinn, Estonia, ${ }^{6)}$ Observatoire de la biodiversité (OBIONE), LIttoral ENvironnement et Sociétés, CNRS/University of La Rochelle, France, ${ }^{7)}$ Sorbonne Universités, UPMC Univ. Paris 06, UMR 7093, LOV, Villefranche-sur-mer, France, ${ }^{8)}$ Sorbonne Universités, UPMC Univ Paris 6, and CNRS, UMR 7144, Station Biologique, Place Georges Teissier, 29680 Roscoff, France, ${ }^{9)}$ Arcachon Marine Station, CNRS, Université de Bordeaux, EPOC, Arcachon, France, ${ }^{10)}$ Institute of Marine Biology, Biotechnology and Aquaculture, Hellenic Centre for Marine Research, Heraklion, Crete, Greece, ${ }^{11)}$ School of Biology and Environmental Science and Earth Institute, University College Dublin, Ireland, ${ }^{12)}$ Department of Biology, University of Pisa, Pisa, Italy, ${ }^{13)}$ CNR, Institute for Coastal Marine Environment, Torregrande, Oristano, Italy, ${ }^{14)}$ Latvian Institute of Aquatic Ecology, Riga, Latvia, ${ }^{15)}$ Marine Science and Technology Centre, Klaipeda University, Lithuania, Klaipeda, Lithuania, ${ }^{16)}$ Institute of Oceanology, Polish Academy of Sciences, Sopot, Poland, ${ }^{17)}$ National Marine Fisheries Research Institute, Gdynia, Poland, ${ }^{18)}$ Marine and Environmental Sciences Centre (MARE), Laboratório de Ciências do Mar, Universidade de Évora, Sines, Portugal, ${ }^{19)}$ Marine and Environmental Sciences Centre (MARE) and Institute of Marine Research (IMAR), University of the Azores, Dpt. of Oceanography and Fisheries, Horta, Portugal, ${ }^{20)}$ Centre for Marine and Environmental Research, CIIMAR, and Faculty of Sciences, University of Porto, 
Portugal, ${ }^{21)}$ ECIMAT, Station of Marine Sciences of Toralla, Dpt of Ecology and Animal Biology, University of Vigo, Spain, ${ }^{22)}$ Environmental Hydraulics Institute, Universidad de Cantabria, Santander, Spain, ${ }^{23)}$ Universidad de Sevilla, Sevilla, Spain, ${ }^{24)}$ Dpt. Ecology and Hydrology, Regional Campus of International Excellence "Campus Mare Nostrum", University of Murcia, Spain, ${ }^{25)}$ Marine Biological Association, Plymouth, UK, ${ }^{26)}$ National Institute of Oceanography, Israel Oceanographic and Limnological Research, Haifa, Israel, ${ }^{27)}$ Ecoauthor, Heinkenszand, the Netherlands

* Corresponding author: Korringaweg 7, 4401 NT Yerseke, the Netherlands; E-mail: herman.hummel@nioz.nl

\section{ABSTRACT}

Within the COST action EMBOS (European Marine Biodiversity Observatory System) the degree and variation of the diversity and densities of soft-bottom communities from the lower intertidal or the shallow subtidal was measured at twenty-eight marine sites along the European coastline (Baltic, Atlantic, Mediterranean) using jointly-agreed and harmonised protocols, tools and indicators. The hypothesis tested was that the diversity for all taxonomic groups would decrease with increasing latitude. The EMBOS system delivered accurate and comparable data on the diversity and densities of the soft sediment macrozoobenthic community over a large-scale gradient along the European coastline. In contrast to general biogeographic theory, species diversity showed no linear relationship with latitude, yet a bell-shaped relation was found. The diversity and densities of benthos were mostly positively correlated with environmental factors such as temperature, salinity, mud and organic matter content in sediment, or wave height, and related with location characteristics such as system type (lagoons, estuaries, open coast) or stratum (intertidal, subtidal). For some relationships, a maximum (e.g. temperature from 15 to $20^{\circ} \mathrm{C}$; mud content of sediment around 40 \%) or bimodal curve (e.g. salinity) was found. In lagoons the densities were twice higher than in other locations, and at open coasts the diversity was much lower than in other locations. We conclude that latitudinal trends and regional differences in diversity and densities are strongly influenced by, i.e. merely the result of, particular sets and ranges of environmental factors and location characteristics specific to certain areas, such as the Baltic, with typical salinity clines (favouring insects) and the Mediterranean, with higher temperatures (favouring crustaceans). Therefore, eventual trends with latitude are primarily indirect and so can be overcome by local variation of environmental factors.

\section{KEYWORDS}

Soft sediment, benthos, species diversity, densities, harmonization of methods, European cline, biogeography, latitudinal diversity gradient (LDG) 


\section{INTRODUCTION}

The marine environment is of transboundary nature and needs to be studied at relevant scales of space and time. For instance, along Europe a north - northeast shift in the distribution of several marine species has been observed (Hummel et al., 2000; Beaugrand et al., 2002; Mieszkowska et al., 2006; Jansen et al., 2007). Global climate change is said to be one of the causes. However, the degree and impact of such biodiversity changes and its causes and consequences remain largely unknown (Heip et al., 2009). Question thereby still is whether changes in the level of diversity in an ecosystem really matter, since despite a huge difference in level and type of diversity between different seas e.g. in the Mediterranean (more than 17,000 plant and animal species), the North Sea (more than 1500 species) the central Baltic (only 73 marine species), trophic relationships in these systems are assumed to be similar (Elmgren \& Hill, 1995; Coll et al., 2010; Magni et al., 2013; Zettler et al., 2014). Determining the patterns of biodiversity of benthic organisms and the factors that may explain them requires an integrated research strategy, which is beyond the tradition, capabilities and scales of classic research (Heip \& Hummel, 2000). The first ideas for such integrated research, involving a large-scale pan-European network of marine observatories, have been formulated during the FP5 (EC $5^{\text {th }}$ Framework Programme) project BIOMARE (Implementation and networking of large scale, long term marine biodiversity research in Europe), which was initiated by the European Network of Marine Research Stations (MARS). The subsequent FP6 Network of Excellence MarBEF (Marine Biodiversity and Ecosystem Functioning) adopted, and focused on, the integration of datasets and joint research (Escaravage et al., 2009; Heip et al., 2009).

These projects have led to recommendations for the selection of sites and indicators to monitor marine ecosystems and their biodiversity at a pan-European scale. The aforementioned activities have been taken under the COST Action ES1003 EMBOS (Development and implementation of a pan-European Marine Biodiversity Observatory System), which lasted from 2011 to 2015. EMBOS focused on the following goals: 1) to build a large-scale pan-European network of marine observatories for biodiversity to overcome fragmentation, 2) to facilitate the monitoring of changes in biodiversity at pan-European scales using harmonized methodologies, and, 3) to assess the feasibility of the EMBOS system through pilot studies.

In a series of surveys during 2014 and 2015 the forty members of EMBOS, representing 22 European countries, have measured at 28 marine sites along the European coastline (Baltic, Atlantic, Mediterranean) the degree and variation of the diversity and densities of hard and soft bottom communities using jointlyagreed and harmonised protocols, tools and indicators. In this paper, we present an overview of the harmonised methods and tools used for sampling and analysis of soft-sediment macrozoobenthos along the European coastline, as well as the results of the first surveys on the geographic patterns of diversity. For the 
soft-sediment benthos the adopted hypothesis was that the diversity for all taxonomic groups would decrease with increasing latitude (see reviews on patterns and causes of the Latitudinal Diversity Gradient (LDG) in Stehli et al., 1967; Schopf et al., 1978; Rohde, 1992; Roy et al., 1998; Gaston, 2000; Willig et al., 2003; Hillebrand, 2004). The results of the surveys carried out in 2014 were used to examine whether this LDG could be found also from our results. Hillebrand (2004) indicated that most studies on LDG comprise only few organism types and are often restricted to certain regions. Because of the harmonised set-up of the EMBOS Pilots we can address these problems and compare data on a wide range of organisms from a wide latitudinal range. Moreover, since we also included environmental data (temperature, salinity, wave height, organic and mud content of the sediment) in our analyses we can elucidate whether the trends in diversity might be explained by these factors regardless of latitude.

The results for the hard bottom benthic communities along the European coastline are reported in Kotta et al. (2016, same volume) focussing on relationships between cover, diversity and environmental factors, in Dal Bello et al. (2016, same volume) with regard to scale-specific variability in community diversity and abundance, and in Puente et al. (2016, same volume) focussing on the role of physical variables in biodiversity patterns of intertidal macroalgae. The results for the functional diversity of the soft bottom benthic communities are reported in Pavloudi et al. (2016, same volume).

\section{MATERIAL AND METHODS}

\section{Sampling procedure}

To assess the trends in diversity in soft-sediment benthic communities along the European coastline, the individual densities of macrozoobenthos species was determined at 28 stations through field surveys from the south to the north of Europe (Figure 1; Table 1). The sampling stations covered a latitudinal cline extending from the Mediterranean, through the Eastern Atlantic and the North Sea to the Baltic (Figure 1). Sampling procedures and treatment and analyses of samples were harmonised for all participants as follows. Sampling was conducted in early spring, given that by being early into, or just before, the reproduction season, then only low numbers of juveniles, if any, are present. Most samples were therefore taken in April, except for those from Crete and one location in Cyprus where samples were taken in May (Table 1). In intertidal areas, sampling was done at low tide, during the day, preferably at noon. In regions without tidal variation, samples were taken at the waterline during calm weather.

When multiple stations within a region were sampled, the stations had a distance of at least two kilometres from each other (Figure 2). At each station, samples were taken at the lower intertidal (i.e. just above Low Water Level $=$ LWL) and/or upper subtidal (UST) level at a maximum depth of two metres. At each level, three plots were chosen parallel to the LWL line, with a distance between plots of 100-200 m. At each plot, three replicate sediment samples with a depth of $30 \mathrm{~cm}$, each at a distance of about two meters, were taken 
with a hand-corer with a diameter of $13 \mathrm{~cm}$ (Figure 3) and sieved over a $0.5 \mathrm{~mm}$ mesh. The residues of the sieved samples were stained with Rose Bengal and preserved in $96 \%$ ethanol or $4 \%$ formaldehyde solution buffered with borax or hexamethylene tetramine. Thus, at each station a total of nine replicates per level were taken. Replicates at the three plots were taken in sediment of comparable granulometry, whereby the median grain size was in between 0.06 and $0.2 \mathrm{~mm}$ (sandy silt). The metadata describing the sampling campaign can be accessed at http://lifewww-00.her.hcmr.gr:8080/medobis/resource.do?r=embos_2014.

\section{Taxonomic analysis}

The residues were sorted in the laboratory under a magnification lamp or stereomicroscope. The macrofauna taxa $(>0.5 \mathrm{~mm}$ ) were determined to the species level, when possible, according to up-to-date taxonomic literature, and their abundance recorded. The most optimal mesh-size for obtaining most macrofaunal species, and to have more realistic abundance values, while comparing different regions, is 0.5 mm (Rees, 1984; Bishop \& Hartley, 1986; Bachelet, 1990; Ferraro \& Cole, 2004; Couto et al., 2010). Species nomenclature followed the World Register of Marine Species (WoRMS) (Costello et al., 2013). Oligochaetes, turbellarians, sponges, nemerteans, insect larvae, and meiofaunal taxa (mainly nematodes and copepods) were not identified to the species level but at the overarching group levels. Incomplete specimens were counted as single individuals if containing the head, whereas other body parts assigned to a given taxon were collectively counted as " 1 " (one). Analysed samples were kept at the individual laboratories for (re)analyses, if needed, at a later stage.

\section{Environmental factors}

In order to analyse species diversity in relation to the main environmental factors, salinity was measured in the surrounding water with a CTD, and sediment temperature with the tip of a thermometer $1 \mathrm{~cm}$ below the surface. Moreover, additional sediment samples were taken for grain size and organic carbon content analyses. For this, two cores per plot were taken from the upper $5 \mathrm{~cm}$ top layer of the sediment with a $3 \mathrm{~cm}$ diameter corer. Samples were pooled per plot and mixed, resulting in three sediment samples per station.

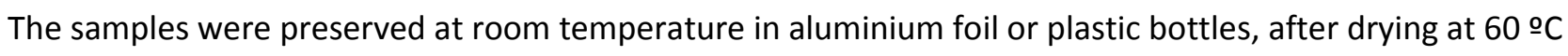
for at least $24-48 \mathrm{~h}$. Shell remains, which were abundant, were removed from the dried sediments with pincers before further sample processing. The sediment samples were centrally analysed by the Institute for Coastal Marine Environment in Torregrande, Oristano, Italy.

Sediment samples (ca. $4 \mathrm{~g}$ ) were pre-treated with $\mathrm{H}_{2} \mathrm{O}_{2}$ (20\% volume) to eliminate organic material, washed with bi-distilled water to eliminate chlorides and then oven-dried at $40{ }^{\circ} \mathrm{C}$ for $12 \mathrm{~h}$. They were subsequently wet sieved in order to obtain the sand fraction $(>63 \mu \mathrm{m})$. Samples were then pre-treated with $\mathrm{Na}$ - 
Hexametaphosphate $0.6 \%$ to avoid particle flocculation for $24 \mathrm{~h}$ and sonicated for $5 \mathrm{~min}$ before analysis. The analysis of mud content $(<63 \mu \mathrm{m})$ was performed using a Galai CIS 1 laser instrument, with specific analytical size intervals of $0.5 \mu \mathrm{m}$ (De Falco et al., 2004). The organic matter (OM) content in the sediments was determined from a subsample (ca. $1 \mathrm{~g}$ ) by loss on ignition (LOI) at $500^{\circ} \mathrm{C}$ for $3 \mathrm{~h}$ (Dean, 1974).

An overview of the stations and the environmental factors used in the analysis is given in Table 1.

To estimate the variations of sea surface temperature (SST) and significant wave height (Hs), data from 1985 to 2013 were acquired by the Instituto de Hidráulica Ambiental de la Universidad de Cantabria (Fundación $\mathrm{IH}$, Santander, Spain) from reanalysis sources at the nearest coastal point with information to the reference points. SST values were supplied, with daily temporal resolution, by the Operational Sea surface Temperature and sea-Ice concentration Analysis (OSTIA) dataset, which is under MyOcean2 project by UKMet Office (NASA) (Stark et al., 2007). Specifically, the Group for High Resolution Sea Surface Temperature (GHRSST) L4 Gap-free gridded products have been used, with a spatial resolution of 0.05․ The wave data used in this work come from the Global Ocean Wave reanalysis database (GOW), reflecting wave height in the open coastal zone (Reguero et al., 2012). Hourly significant wave height data were extracted with a spatial resolution of 0.125 o for all sites. Salinity was obtained from in situ measurements provided by the World Ocean Database (WOD) of the National Oceanic and Atmospheric Administration (NOAA)-NESDIS National Oceanographic Data Centre (NODC) (Levitus et al., 2013). The salinity profiles used in this study were acquired between 1985 and 2014, and due to the sparse available data, for each station the salinity value was calculated as the average of all data points within a circle of 0.4 o radius in the first $40 \mathrm{~m}$ around the reference points.

\section{Statistical analysis}

Differences in macrozoobenthic assemblages between regions and/or subregions were analyzed using a non-metric multidimensional-scaling (nmMDS) ordination model based on the Bray-Curtis dissimilarity matrix (Clarke \& Warwick, 2001) calculated on the mean values among the three replicate samples within each plot. A one-way ANOSIM randomization/permutation test was used to check for the significance of differences among regions (i.e. Baltic, Atlantic and Mediterranean regions) in the ordination model (Clarke \& Warwick, 2001). A one-way ANOSIM was also used to check for the significance of differences among subregions (see Tables $2 a$ and $2 b$ for respectively the identification of the regions and the sub-regions). All data were square-root transformed prior to the analyses, to minimise the effect of dominant species (Clarke $\&$ Warwick, 2001). One of the plots from Cyprus (Softades-Larnaca1) was excluded from the analyses as no fauna was found in each of the three replicates. MDS 2D representations were considered acceptable when 
the stress factor did not transgress the value of 0.2 (Clarke \& Warwick, 2001). nmMDS and ANOSIM were conducted with the PRIMER v6.1.12 package (Clarke \& Gorley, 2006).

Hierarchical clustering and ordination methods were performed to identify, analyse, and compare the multivariate pattern of soft sediment macrozoobenthic assemblages based on diversity and density descriptors (number of species (S), total density (n), Margalef species richness $(d=(S-1) / \ln (n)$ ), Shannon diversity $\left(H^{\prime}=-\sum p_{i}\left(\ln \left(p_{i}\right)\right)\right.$ and Pielou evenness $\left(J^{\prime}=\left(H^{\prime} / \ln (S)\right)\right.$ per sample with $p_{i}$ being the proportion of species $\mathrm{i}$ in the sample) and environmental and geographic location characteristics. Multivariate analyses based on community descriptors were used as an initial analysis solely based on densities for each of the species resulted in poor relations with environmental descriptors because the locations to compare at European scale each had a rather unique species composition with few species in common. A Principal Component Analysis (PCA), an indirect gradient analysis (i.e. ordination with optimal gradient distribution solely based on 'species' data, with plotting of environmental and location specific characteristics afterwards to identify potential relations), was performed on ' $I n(x+1)$ '-transformed data, using the CANOCO for Windows version 4.5 software package (Ter Braak \& Smilauer, 1998). A Detrended Correspondence Analysis (DCA) showed that the data had a short gradient length, which allowed the use of a linear ordination method. In the PCA analysis, environmental and location-specific characteristics with little explanatory power towards the observed patterns in species compositions, or highly co-varying with other characteristics, are not shown in the PCA results, as omitting (or adding) potential explanatory parameters does not have an influence on the ordination results in an indirect analysis.

The total macrozoobenthic densities (subdivided in abundances for larger taxonomical groups) were plotted in bar-graphs against the environmental factors that showed the best explanatory power in the PCA analysis (subdivided into classes from low to high values). Significant differences in total densities between identified classes were tested by using 2-side t-tests after testing for similarity of variances (F-tests) in Microsoft Excel 2010.

Additional graphs were plotted identifying relations of Shannon diversity $\left(\mathrm{H}^{\prime} \log \mathrm{e}\right)$ and total macrozoobenthos densities (the average of 3 replicates per sampling plot) with the environmental parameters. Because diversity indicators such as $\mathrm{S}, \mathrm{d}, \mathrm{J}^{\prime}$ and $\mathrm{H}^{\prime}$ are highly correlated, as can be expected since they are calculated on the basis of the same elements, the focus was on Shannon diversity $\left(\mathrm{H}^{\prime}\right)$ as community descriptor. Best fitting regressions were calculated starting from linear regression through a quadratic and cubic, to maximally a quartic (polynomial) regression, assuming that $r^{2}$ should increase at least $10 \%$ in order to adopt a higher polynomial level as being better fitting $\left(r^{2}\right.$ will always increase at a higherorder term, but it is hard to imagine a biological meaning for exponents greater than 3) (McDonald, 2014). 


\section{RESULTS}

\section{Relations of major taxonomic groups with latitude and region}

Multivariate analyses (MDS and ANOSIM) revealed differences in the densities-based species composition of macrozoobenthic assemblages among the Baltic, Atlantic and Mediterranean regions (Figure 4a; Table 2a). We also found a significant differentiation between most sub-regions as indicated by the pairwise test (Figure 4b; Table 2b). In particular, all Mediterranean sub-regions (i.e. Eastern Mediterranean, Sea of Crete, Ionian Sea and Western Mediterranean) were significantly different from each other (Table 2b), with the highest $R$ value when comparing the Eastern with the Western sub-region $(R=0.879, \mathrm{P}<0.001$; Table $2 \mathrm{~b})$. In contrast, most Atlantic sub-regions (i.e. Atlantic Ocean, English Channel and North Sea) did not significantly differ ( $p>0.10$; Table $2 b$ ), except for the Bay of Biscay which is different from all other subregions.

The distribution of the mean densities of the major taxonomic groups (expressed in absolute and relative terms) varied with latitude (Figure 5), reflecting the major differentiation among regions and sub-regions as revealed by multivariate analyses. The following major trends were found: 1 ) at low latitudes (= Eastern Mediterranean at $32-36^{\circ} \mathrm{N}$ ): very low densities of all groups, 2) at somewhat higher latitudes (= Western Mediterranean $>36^{\circ} \mathrm{N}$ ): high densities of mainly Malacostraca (crustaceans), 3) middle latitudes (= Atlantic and North Sea): intermediate densities, with a dominance of Polychaetes, 4) high latitudes (= Baltic): intermediate densities with mainly insects.

\section{Relations of major taxonomic groups with environmental factors and location characteristics}

The densities of all major taxonomic groups together (i.e. total densities) did not show a consistent pattern in relation to salinity (Figure 6a). Yet, for each separate taxonomic group a specific relation with salinity was found (Figure 6b). Both in absolute as well as in relative terms, insects were mainly found at low salinities, and crustaceans (Malacostraca) at higher salinities. Polychaetes were found equally at all salinities, whereas bivalves and gastropods were not present at the lowest salinities. These results corroborate the abovedescribed results on the distribution of taxa by region, as low salinities occur in the Baltic, where mainly insects were found, and high salinities are found in the Mediterranean favouring the crustaceans.

Densities of major taxonomic groups were higher at higher temperatures (Figure 7A). The insects, mainly occurring in the Baltic (Figure 7B), were found at low temperatures (as do occur in the Baltic in early spring). The crustaceans (Malacostraca), and especially the bivalves, were found mainly at higher temperatures, while polychaetes were found equally at all temperatures. 
Densities of all taxonomic groups increased with increasing mud content (Figure 8a) as well as with increasing organic matter content (Figure 9a). Values levelled off at a mud content percentage higher than 12 to $24 \%$.

All taxonomic groups showed a relatively similar increase of densities at higher mud or organic matter content, so the relative distribution of taxonomic groups at different levels of mud or organic matter remained rather similar (Figures $8 b, 9 b$ ).

The total density was highest at the lowest wave height (Figure 10a). That pattern was also observed for the bivalves, whereas the density of polychaetes showed an opposite trend with highest densities at the highest wave heights (Figure 10b)

The total density was on an average two times higher in lagoons than in estuaries or the open coast - the last two having similar densities (Figure 11a). The densities were higher at subtidal than at intertidal stations (Figure 11a). At intertidal stations in estuaries the polychaetes are more dominant than in other stations, and in the open coast stations the crustaceans dominate (Figure 11b).

\section{Variation in community diversity and densities, and environmental variables}

The Principal Component Analysis (PCA), based on the diversity and abundances of benthic communities, showed that the (variance in) environmental and geographic location characteristics coincided strongly with the (variance in) macrozoobenthos diversity (Shannon $\mathrm{H}^{\prime}$ ) and densities (> 90\%; Table 3). Regarding geographic location most variance coincided with that of the main geographic regions Atlantic (positively correlated to that of diversity) and Baltic (negatively correlated) (Figure 12). Moreover, the (variance in) diversity showed a strong positive correlation with that of the (variance in) major environmental factors and location characterisics (salinity, temperature, mud content, organic matter content, wave height, the estuarine system type, and intertidal stratum) (Figure 12, Table 3). At the other hand, the (variance in) diversity was negatively correlated with that of the factor 'open coast', which corresponds to the much lower diversity at open coasts than at the other locations (in estuaries or lagoons; Figure 13).

The variance in densities was only marginally explained by the measured environmental factors (Figure 12). Yet, the location characteristics 'lagoon' and 'open coast' were strongly, positive respectively negative, correlated with the (variance in) densities. Clearly the densities at open coast stations are much lower than in lagoons (Figure 13). The lower explanatory level of the measured environmental factors for the variance in densities, in comparison to that for diversity, also became clear from an analysis of the relationship between the individual factors, as indicated in the following section. 


\section{Relation of benthic diversity and total densities with environmental factors}

Benthic diversity was highest at latitudes from 40 to $45^{\circ} \mathrm{N}$ (Figure 14a). The highest overall densities

(including all species) were found at $40^{\circ} \mathrm{N}$ (southern Atlantic Ocean; Bay of Biscay) in comparison to lower as well as higher latitudes (Figure 14b). The highest soft-sediment benthic diversity and densities were found in areas with annual average SST of 15 to $20^{\circ} \mathrm{C}$ (Figure $15 \mathrm{a}, \mathrm{b}$ ). The curves of the diversity and density variation with increasing temperature (Figure 15) were the reverse (mirror images) of those found for latitude (Figure 14), as was to be expected since temperature is generally inversely related to latitude. The lowest diversity values were found at salinities below 10, whereas the higher diversities were mainly found above $15 \mathrm{ppt}$ (Figure 16a). Although no clear trend was found for densities, it appears that high densities occurred primarily at salinities above 20 ppt (Figure 16b).

Diversity and densities sharply increased with mud content between 0 to $10 \%$ (Figure 17a, b) but slightly decreased at the highest levels (> 40\%). A similar relation was found between organic matter content and diversity (Figure 18a), while no decrease at higher levels was found for the densities (Figure 18b).

The diversity of macrozoobenthos increased at increasing average wave heights from 0.4 to $1.4 \mathrm{~m}$ in coastal areas (Figure 19a) and decreased again at higher wave heights. For the densities no clear relation with wave height could be found (Figure 19b).

\section{DISCUSSION}

Patterns in diversity are often related to latitude, a phenomenon known as the latitudinal diversity gradient (LDG), whereby a decrease with increasing latitude is found (Roy et al., 1998; Rex et al., 2000; Attrill et al., 2001; Willig et al., 2003; Hillebrand, 2004). Several hypotheses for the underlying causes for such pattern are suggested, yet none of them is solely sufficiently convincing (Willig et al., 2003; Hillebrand, 2004), although solar energy input (and for the marine territory the sea surface temperature as its proxy) is most often mentioned as the main acting principle (Rohde, 1992; Roy et al., 1998). In corroboration to this rule we indeed found a positive relation between temperature and diversity. However, the curve with temperature is bell-shaped, i.e. at higher temperatures the diversity decreases again. This decrease could be related to the physiological limit at higher temperatures in marine invertebrates (Newell, 1979), a situation that occurred in our study in the South-Eastern Mediterranean.

This means also that in our study a low diversity at the lower (Mediterranean) latitudes was found. Therefore, in contrast to the general LDG pattern, in our study for benthic species of soft substrates the highest diversity (as well as densities) was found at latitudes around 40 to $50^{\circ} \mathrm{N}$, while lower diversity (and densities) was found at lower and higher latitudes. Deviations from the general LDG pattern have also been 
reported before for European marine benthos by Renaud et al. (2009) who found no or weakly positive relationships. The explanation for this kind of diverting trends is that the impact of (local variation in) environmental factors is stronger than that of latitude related factors (Gaston, 2000; Renaud et al., 2009).

One of the factors, not related to latitude yet influencing the diversity, is salinity. A higher diversity with higher average salinity, as observed in our dataset, is in line with the classical Remane pattern of larger species richness at marine conditions compared to brackish conditions (Remane, 1934; Attrill, 2002). A slight increase of diversity near freshwater conditions was also found in our results. However, in contrast to the classical pattern, a depression in diversity was also found at salinities around 35 to 40 ppt, which is just above the regular sea water salinity. These higher salinities occurred in the South-Eastern Mediterranean and thus may help to explain the lower diversity at these latitudes.

Other environmental factors relating to diversity and density, that could also be causative for deviations from the LDG, were organic matter and mud content of the sediment and wave height. An increase of all these factors resulted in higher diversity, up to a certain maximum or threshold level above which the diversity decreased. The decrease at high levels, resulting in a bell-shaped curve, may be because sediments with e.g. high mud and/or organic content could be too swampy or anoxic and thereby unsuitable for benthic animals (Pearson \& Rosenberg, 1978; Hyland et al., 2005; Magni et al., 2008).

In addition to latitudinal variation, also the longitudinal differentiation should be taken into account. This can be explained by the variation within regions, as the lowest salinities can be found towards the East in the Baltic (Bonsdorff, 2006), and the lowest wave heights and highest temperatures in the East of the Mediterranean (Lejeusne et al., 2010). Each of these 'extreme' environmental conditions, coinciding with a lower diversity, exists in the Eastern part for both regions (the Baltic and Mediterranean), thereby giving result to the observed strong axis for longitude in the multivariate analysis. Moreover, the lower diversity in the east of the Mediterranean might also be related to lower primary production in the East compared to the West (Bricaud et al., 2002), whereby the carrying capacity of the Eastern Mediterranean might be lower.

At an even smaller (sub-regional) scale, a remarkable result was the difference of the Bay of Biscay compared to the, among each other similar, NE Atlantic, North Sea and English Channel sub-regions. In the Bay of Biscay, SST is known to be higher than in the surrounding areas connected by the Gulf Stream (Jenkins et al., 2008), which may explain the much higher community resemblance to the Moroccan coast and Mediterranean than the adjacent subregions (Jenkins et al., 2008), as observed also for macroalgae (Sauvageau, 1897; Fischer-Piètte, 1955). 
In addition to the correlation with environmental factors and (sub)regions a relation was found with location characteristics. The higher diversity in estuaries and lagoons, than at open coast, corroborates other studies and is normally attributed to the higher diversity of habitats (ecotones) and the higher production in those systems (de Wit, 2011; Miththapala, 2013). The higher densities in lagoons are also corroborated by these authors, and attributed to the edge-effect, i.e. higher numbers at locations where different habitats/ecotones meet each other.

However, some of the above mentioned, environmental as well as geographic influencing factors may coincide and cannot be fully teased apart with the current sampling scheme, as e.g. latitude and temperature, or salinity and longitudinal location in the Baltic. Further integrated studies, and thus an extension of the harmonised EMBOS approach and an even wider geographic coverage, may be needed to overcome this kind of multicollinearity and to reach a stronger conclusion.

In summary, the differentiation in diversity and densities of macrozoobenthos and in environmental factors coincides with strong interregional differentiation, especially between the Atlantic and the Baltic, as seen in the PCA analysis. In the Atlantic, much higher values of salinity, temperature, mud and organic matter content in the sediments, as well as wave heights are observed. Therefore, it can be suggested that the latitudinal and regional differences found in densities and diversity are strongly determined by the environmental differentiation between the Baltic (low salinities, no tide), the Atlantic (high mud and organic matter content in sediment, moderate temperature and salinity, high average wave heights) and the Mediterranean (high temperatures, high salinity, small tide).

Consequently, some soft substrata taxa are numerically more dominant in one region or the other, e.g. crustaceans in the Mediterranean, polychaetes in the Atlantic, and insects in the northern Baltic. Thus, it may be argued that latitudinal trends and regional differences in diversity and densities are merely a result of including very different bodies of water in this survey, which is unlike testing a continuous gradient along a single coast line; i.e. the two extremes, the Baltic which is a semi-enclosed sea with very low salinities favouring a high proportion of insects (Bonsdorff, 2006), vs. the Mediterranean, also a semi-enclosed sea yet with relatively high salinities and high temperatures favouring a high proportion of crustaceans. However, what should be taken into account is that these two enclosed bodies of water also have very different histories, the former being much younger than the latter, which can also affect diversity levels through evolutionary processes (Bonsdorff, 2006; Nordström et al., 2010).

Taking all results together, it can be concluded that the hypothesis expecting a negative linear gradient in diversity with latitude was not supported, as the highest observed diversity was observed at latitudes 
between 40 and $45^{\circ} \mathrm{N}$. This bell shaped relationship is most probably driven by large differences in environmental factors that are not merely determined by latitude.

However, the latitudinal range of this study is restricted to 30 to $60 \% \mathrm{~N}$, which should be preferably extended over the whole latitudinal gradient in order to obtain a better understanding of this hypothesis.

Moreover, the accuracy of the observed patterns between diversity or densities and environmental parameters can be improved by using in situ measurements instead of remote sensing data. In this study remote sensing data were probably not always sufficiently detailed to get accurate values for semi-enclosed areas, whereby the relationships with diversity and densities were not optimal. Further, to improve the resolution of relations between environmental factors and densities, seasonality should be taken into account, since in invertebrates the densities normally show strong annual fluctuations and thus much weaker relationships with environmental factors than will be (and thus were) found for (the less fluctuating) diversity.

\section{CONCLUSION}

Conclusions of this study are:

- By employing harmonized tools and methodologies, the EMBOS system delivered an extensive comparable dataset on the diversity and densities of the soft sediment macrozoobenthic community over a large-scale gradient along the European coastline - Species diversity has no linear (negative) relationship with latitude, yet in deviation to general theory, a bell-shaped relation is found in the studied latitudinal range.

- In general, the diversity or densities of soft-sediment macrozoobenthos were positively related with environmental factors such as temperature, salinity, mud and organic matter content in sediment, and wave height. For some relationships an optimum curve (e.g. temperature from 15 to $20^{\circ} \mathrm{C}$; mud content of sediment around $40 \%$ ) or bimodal curve (e.g. salinity) was found. Densities were also higher at lagoon and subtidal stations (versus estuarine, open coastal and intertidal stations).

- Latitudinal trends and regional differences in diversity and densities are merely the result of including areas with specific set and ranges of environmental factors, such as the Baltic with typical salinity clines (favouring insects) and the Mediterranean with higher temperatures (favouring crustaceans). Therefore, putative latitudinal trends are indirect.

\section{FINANCIAL SUPPORT AND ACKNOWLEDGEMENTS}

This article is based upon work from COST Action ES1003 Development and implementation of a panEuropean Marine Biodiversity Observatory System (EMBOS), supported by COST (European Cooperation in Science and Technology). Jonne Kotta, and Helen Orav-Kotta were supported by Institutional research 
funding IUT02-20 of the Estonian Research Council and the BONUS project BIOC3, the joint Baltic Sea research and development programme (Art 185), funded jointly from the European Union's Seventh Programme for research, technological development and demonstration and from Estonian Research Council. Pedro Ribeiro and Puri Veiga were supported by the Portuguese Science Foundation (FCT) through a post-doctoral grant (ref. SFRH/BPD/69232/2010 and SFRH/BPD/81582/2011, respectively). Valentina de Matos was supported by the Portuguese Science Foundation (FCT) through a doctoral grant (ref. SFRH/BD/86390/ 2012). Jérôme Jourde was financially supported by the Région Poitou-Charentes through CPER funding, La Rochelle University and CNRS. Martina Dal Bello and Lisandro Benedetti-Cecchi were supported by a grant from the Italian Ministry for Research and Education (PRIN project "Biocostruzioni costiere: struttura, funzione, e gestione"). The authors want to thank Dimitra Mavraki, Matina Nikolopoulou, Nicolas Bailly (of HCMR), Alina Sousa, André Costa, Cristina Santo, João Castro, Marta Mamede, Nuno Mamede, Susana Celestino (of MARE-UE), Hugues Blanchet, Xavier de Montaudouin, Benoît Gouillieux, Michel Leconte (of Arcachon Marine Station), Laureen Beaugeard and Clément Chaigneau (of University of La Rochelle), Concepción Marcos, Jessica Titocci, Antonio Sala Mirete and Jose Gabriel Hernández (of University of Murcia) for support given during sampling and analyses. Emilia Jankowska and Jan Marcin Węsławski were supported by the Statutory Funds of the Institute of Oceanology, Polish Academy of Sciences. A. Satta, CNR-IAMC Oristano, is acknowledged for sediment analysis. Jan Warzocha, Sławomira Gromisz and Bartosz Witalis (NMFRI) were supported by Statutory Funds from Polish Ministry of Science and Higher Education (ref. P1-3/2012-2014).

\section{REFERENCES}

Attrill M.J., Stafford R. and Rowden A.A. (2001) Latitudinal diversity patterns in estuarine tidal flats: indications of a global cline. Ecography, 24, 318-324.

Attrill M.J. (2002) A testable linear model for diversity trends in estuaries. Journal of Animal Ecology, 71, 262-269.

Bachelet G. (1990) The choice of a sieving mesh size in the quantitative assessment of marine macrobenthos: a necessary compromise between aims and constraints. Marine Environmental Research 30: 21-35.

Bishop J.D.D. and Hartley J.P. (1986) A comparison of the fauna retained on $0.5 \mathrm{~mm}$ and $1.0 \mathrm{~mm}$ meshes from benthic samples taken in the Beatrice Oilfield, Moray Firth, Scotland. Proceedings of the Royal Society of Edinburgh 91B: 247-262.

Bonsdorff E. (2006) Zoobenthic diversity-gradients in the Baltic Sea: Continuous post-glacial succession in a stressed ecosystem. Journal of Experimental Marine Biology and Ecology, 330, 383-391. 
Bricaud A., Bosc E. and Antoine D. (2002) Algal biomass and sea surface temperature in the Mediterranean Basin. Intercomparison of data from various satellite sensors, and implications for primary production estimates. Remote Sensing of Environment, 81, 163-178.

Beaugrand C., Reid P.C., Ibanez F., Lindley J.A. and Edwards M. (2002) Reorganization of North Atlantic marine copepod biodiversity and climate. Science, 296, 1692-1694.

Clarke K.R. and Warwick R.M. (2001) Changes in Marine Communities: An Approach to Statistical Analysis and Interpretation. 2nd edition. Natural Environment Research Council, United Kingdom Plymouth, 358 UK: PRIMER-E, 142 pp.

Clarke K.R. and Gorley R.N. (2006) PRIMER v6: User manual/tutorial. PRIMER-E, Plymouth, UK, p. 192.

Coll M., Piroddi C., Steenbeek J., Kaschner K., Ben Rais Lasram F., Aguzzi J., Ballesteros E., Bianchi C.N., Corbera J., Dailianis T., Danovaro R., Estrada M., Froglia C., Galil B.S., Gasol J.M., Gertwagen R., Gil J., Guilhaumon F., Kesner-Reyes K., Kitsos M.S., Koukouras A., Lampadariou N., Laxamana E., López-Fé de la Cuadra C.M., Lotze H.K., Martin D., Mouillot D., Oro D., Raicevich S., Rius-Barile J., Saiz-Salinas J.I., San Vicente C., Somot S., Templado J., Turon X., Vafidis D., Villanueva R. and Voultsiadou E. (2010) The biodiversity of the Mediterranean Sea: estimates, patterns, and threats. PLoS One, 5(8):e11842.

Costello M.J., Bouchet P., Boxshall G., Fauchald K., Gordon D., Hoeksema B.W., Poore G.C.B., van Soest R.W.M., Stöhr S, Walter T.C., Vanhoorne B., Decock W. and Appeltans W. (2013) Global Coordination and Standardisation in Marine Biodiversity through the World Register of Marine Species (WoRMS) and Related Databases. PLoS One, 8, e51629. doi: 10.1371/journal.pone.0051629.

Couto T., Patricio J., Neto J.M., Ceia F.R., Franco J. and Marques J.C. (2010) The influence of mesh size in environmental quality assessment of estuarine macrobenthic communities. Ecological Indicators 10: 1162-1173.

Dal Bello M., Leclerc J.C., Benedetti-Cecchi L., Arvanitidis C., van Avesaath P., Bachelet G., Bojanic N., Como S., Coppa S., Coughlan J., Crowe T., Degraer S., Espinosa F., Faulwetter S., Frost M., Guinda X., Jankowska E., Jourde J., Kerckhof F., Kotta J., Lavesque N., de Lucia G.A., Magni P., Fernandes de Matos V.K., Orav-Kotta H., Pavloudi C., Pedrotti M.L., Peleg O., Juanes de la Pena J.A., Puente A., Ribeiro P., Rigaut-Jalabert F., Rilov G., Rousou M., Rubal M., Ruginis T., Ruzafa A., Silva T., Simon N., Sousa-Pinto I., Troncoso J., Warzocha J., Weslawski J.M. and Hummel H. (2016) Consistent patterns of spatial variability between Atlantic and Mediterranean rocky shores. Journal of the Marine Biological Association of the United Kingdom (accepted, this volume)

Dean W.E. (1974) Determination of carbonate and organic matter in calcareous sediments and sedimentary rocks by loss on ignition: comparison with other methods. Journal Sedimentary Petrology, 44, 242-248. 
De Falco G., Magni P., Teräsvuori L. and Matteucci G. (2004) Sediment grain size and organic carbon distribution in the Cabras lagoon (Sardinia, west Mediterranean). Chemistry and Ecology, 20(S1), S367S377.

De Wit R. (2011). Biodiversity of coastal lagoon ecosystems and their vulnerability to global change. In: Ecosystems biodiversity. O. Gillo \& G. Venora (eds). Intech. Rijeka, Croatia. pp 29-40.

Elmgren R. and Hill C. (1995) Ecosystem function at low biodiversity - the Baltic example. In: Marine Biodiversity Patterns and Processes. R.F.G. Ormond, J.D. Gage \& M.V. Angel (eds). Cambridge University Press, Cambridge. pp 319-336.

Escaravage V., Herman P. M. J., Merckx B., Wlodarska-Kowalczuk M., Amouroux J. M., Degraer S., Grémare A., Heip C. H. R., Hummel H., Karakassis I., Labrune C. and Willems W. (2009) Distribution patterns of macrofaunal species diversity in subtidal soft sediments: biodiversity-productivity relationships from the MacroBen database. Marine Ecology Progress Series, 382, 253-264.

Ferraro S.P. and Cole F.A. (2004) Optimal benthic macrofaunal sampling protocol for detecting differences among four habitats in Willapa Bay, Washington, USA. Estuaries, 27, 1014-1025.

Fischer-Piètte, E. (1955) Répartition le long des côtes septentrionales de l'Espagne des principales espèces peuplant les rochers intercotidaux. Annales de I'Institut Oceanographique, 31, 38-124.

Gaston K. J. (2000) Global patterns in biodiversity. Nature, 405, 220-227.

Heip C. and Hummel H. (2000) Establishing a framework for the implementation of marine biodiversity research in Europe. European Science Foundation, ESF Marine Board Report, Strasbourg, France, 48 pp.

Heip C., Hummel H., van Avesaath P., Appeltans W., Arvanitidis C., Aspden R., Austen M., Boero F., Bouma T.J., Boxshall G., Buchholz F., Crowe T., Delaney A., Deprez T., Emblow C., Feral J.P., Gasol J.M., Gooday A., Harder J., lanora A., Kraberg A., Mackenzie B., Ojaveer H., Paterson D., Rumohr H., Schiedek D., Sokolowski A., Somerfield P., Sousa Pinto I., Vincx M., Weslawski J.M. and Nash R. (2009) Marine biodiversity and Ecosystem Functioning, ISSN 2009-2539, 91 pp.

Hillebrand H. (2004) On the generality of the latitudinal diversity gradient. The American Naturalist 163, $192-211$.

Hummel H., Bogaards R.H., Bachelet G., Caron F., Sola J.C. and Amiard-Triquet C. (2000) The respiratory performance and survival of the bivalve Macoma balthica at the southern limit of its distribution area: a translocation experiment. Journal of Experimental Marine Biology and Ecology, 251, 85-102.

Hyland J., Balthis L.W., Karakassis I., Magni P., Petrov A., Shine J.R., Vestergaard O. and Warwick R. (2005) Organic carbon content of sediments as an indicator of stress in the marine benthos. Marine Ecology Progress Series, 295, 91-103.

Jansen, J.M., Pronker S.A.E., Kube S., Sokolowski A., Sola J.C., Marquiegui M., Schiedek D., Wolowicz M., Wendelaar Bonga S. and Hummel H. (2007) Geographic and seasonal patterns and limits in the 
adaptive response to temperature of European Mytilus spp. and Macoma balthica populations. Oecologia, 154, 23-34

Jenkins S.R., Moore P., Burrows M.T., Garbary D.J., Hawkins S.J., Ingolfsson A., Sebens K.P., Snelgrove P.V.R., Wethey D.S. and Woodin S.A. (2008) Comparative ecology of North Atlantic shores: Do differences in players matter for process? Ecology, 89 (11), Supplement, S3-S23.

Kotta J., Orav-Kotta H., Jänes H., Hummel H., Arvanitidis C., van Avesaath P., Bachelet G., Benedetti-Cecchi L., Bojanic N., Como S., Coppa S., Coughlan J., Crowe T., Dal Bello M., Degraer S., Juanes de La Pena J.A., Fernandes de Matos V.K., Espinosa F., Faulwetter S., Frost M., Guinda X., Jankowska E., Jourde J., Kerckhof F., Lavesque N., Leclerc J.C., Magni P., Pavloudi C., Pedrotti M.L., Peleg O., Pérez-Ruzafa A., Puente A., Ribeiro P., Rilov G., Rousou M., Ruginis T., Silva T., Simon N., Sousa-Pinto I., Troncoso J., Warzocha J. and Weslawski J.M. (2016) Essence of the patterns of cover and richness of intertidal hard bottom communities: a pan-European study. Journal of the Marine Biological Association of the United Kingdom (accepted, this volume)

Lejeusne C., Chevaldonne P., Pergent-Martini C., Boudouresque C.F. and Perez, T. (2010) Climate change effects on a miniature ocean: the highly diverse, highly impacted Mediterranean Sea. Trends in Ecology \& Evolution, 25, 250-260.

Levitus S., Antonov J.I., Baranova O.K., Boyer T.P., Coleman C.L., Garcia H.E., Grodsky A.I., Johnson D.R., Locarnini R.A., Mishonov A.V., Reagan J.R., Sazama C.L., Seidov D., Smolyar I., Yarosh E.S. and Zweng M.M. (2013) The World Ocean Database. Data Science Journal, 12, WDS229-WDS234.

Magni P., De Falco G., Como S., Casu D., Floris A., Petrov A.N., Castelli A. and Perilli A. (2008) Distribution and ecological relevance of fine sediments in organic-enriched lagoons: the case study of the Cabras lagoon (Sardinia, Italy). Marine Pollution Bulletin, 56, 549-564.

Magni P., Rajagopal S., Como S., Jansen J.M., van der Velde G. and Hummel H. (2013) $\delta^{13} \mathrm{C}$ and $\delta^{15} \mathrm{~N}$ variations in organic matter pools, Mytilus spp. and Macoma balthica along the European Atlantic coast. Marine Biology, 160, 541-552.

McDonald J.H. (2014) Handbook of Biological Statistics (3rd ed.). Sparky House Publishing, Baltimore, Maryland, 213-219.

Mieszkowska N., Kendall M.A., Hawkins S.J., Leaper R., Williamson P., Hardman-Mountford N.J. and Southward A.J. (2006) Change in the range of some common rocky shore species in Britain - a response to climate change? Hydrobiologia, 555, 241-251.

Miththapala, S. (2013). Lagoons and estuaries. Coastal Ecosystems Series, Vol 4. IUCN, SriLanka Country Office, Colombo, 73 pp.

Newell R.C. (1979) Biology of intertidal organisms, 3rd ed. Marine Ecological Surveys, Ltd., Kent, 781 pp. 
Nordström M., Lindblad P., Aarnio K. and Bonsdorff E. (2010) A neighbour is a neighbour? Consumer diversity, trophic function, and spatial variability in benthic food web. Journal of Experimental Marine Biology and Ecology, 391, 101-111.

Pavloudi C., Faulwetter S., Keklikoglou K., Vasileiadou K., Chatzinikolaou E., Mavraki D., Nikolopoulou M., Bailly N., Rousou M., Kotta J., Orav-Kotta H., Bachelet G., Lavesque N., Benedetti-Cecchi L., Dal Bello M., Bojanic N., Como S., Coppa S., Magni P., Coughlan J., Crowe T., Degraer S., Juanes de la Pena J.A., Guinda X., Puente A., Fernandes de Matos V.K., Ribeiro P., Espinosa F., Kerckhof F., Jankowska E., Weslawski J.M., Peleg O., Rilov G., Pérez-Ruzafa A., Ruginis T., Jourde J., Leclerc J.C., Simon N., Pedrotti M.L., Silva T., Sousa-Pinto I., Rubal M., Troncoso J., Warzocha J., van Avesaath P., Frost M., Hummel H. and Arvanitidis C. (2016) Taxonomic vs functional patterns across European marine benthic habitats. Journal of the Marine Biological Association of the United Kingdom (submitted)

Pearson T.H. and Rosenberg R. (1978) Macrobenthic succession in relation to organic enrichment and pollution of the marine environment. Oceanography and Marine Biology, Annual Reviews, 16, 229-311.

Puente A., Guinda X., Juanes de la Pena J.A., Echavarri-Erasun B., Ramos E., de la Hoz C.F., Degraer S., Kerckhof F., Bojanic N., Rousou M., Orav-Kotta H., Kotta J., Jourde J., Pedrotti M.L., Leclerc J.C., Simon N., Bachelet G., Lavesque N., Arvanitidis C., Pavloudi C., Faulwetter S., Crowe T., Coughlan J., Benedetti-Cecchi L., Dal Bello M., Magni P., Como S., Coppa S., de Lucia A., Ruginis T., Jankowska E., Wesławski J.M., Warzocha J., Silva T., Ribeiro P., Fernandes de Matos V.K., Sousa-Pinto I., Troncoso J., Peleg O., Rilov G., Espinosa F., Pérez-Ruzafa A., Frost M., Hummel H. and van Avesaath P. (2016) The role of physical variables in biodiversity patterns of intertidal macroalgae along European coasts. Journal of the Marine Biological Association of the United Kingdom (accepted, this volume)

Rees H.L. (1984) A note on mesh selection and sampling efficiency in benthic studies. Marine Pollution Bulletin 15: 225-229.

Reguero B.G., Menéndez M., Méndez F.J., Mínguez R., Losada I.J. (2012) A Global Ocean Wave (GOW) calibrated reanalysis from 1948 onwards. Coast England, 65, 38-55.

Remane A. (1934) Die Brackwasserfauna. Zoologischer Anzeiger (Suppl.), 7, 34-74.

Renaud P.E., Webb T.J., Bjørgesæter A., Karakassis I., Kędra M., Kendall M.A., Labrune C., Lampadariou N., Somerfield P.J., Włodarska-Kowalczuk M., Vanden Berghe E., Claus S., Aleffi I.F., Amouroux J.M., Bryne K.H., Cochrane S.J., Dahle S., Degraer S., Denisenko G., Deprez T., Dounas C., Fleischer D., Gil J., Grémare A., Janas U., Mackie A.S.Y., Palerud R., Rumohr H., Sardá R., Speybroeck J., Taboada S., Van Hoey G., Węsławski J.M., Whomersley P. and Zettler M.L. (2009) Continental-scale patterns in benthic invertebrate diversity: insights from the MacroBen database. Marine Ecology Progress Series, 382, 239252. 
Rex M.A., Stuart C.T. and Coyne G. (2000) Latitudinal gradients of species richness in the deep-sea benthos of the North Atlantic. Proceedings of the National Academy of Sciences of the USA, 97, 4082-4085.

Rohde K. (1992) Latitudinal gradients in species diversity: the search for the primary cause. Oikos, 65, 514527.

Roy K., Jablonski D., Valentine J.W. and Rosenberg G. (1998) Marine latitudinal diversity gradients: Tests of causal hypotheses. Proceedings of the National Academy of Sciences of the USA, 95, 3699-3702.

Sauvageau C. (1897) Note préliminaire sur les algues marines du Golfe de Gascogne. Journal de Botanique, 11, 166-307.

Schopf T.J.M., Fisher J.B. and Smith III C.A.F. (1978) Is the marine latitudinal gradient merely another example of the species area curve?. In Battaglia B. and Beardmore J.A. (eds). Marine organisms. Genetics, Ecology and Evolution. Plenum Press, New York, USA, pp. 365-389.

Stark J.D., Donlon C.J., Martin M.J., McCulloch M.E. (2007) OSTIA : An operational, high resolution, real time, global sea surface temperature analysis system. In OCEANS 2007. Marine challenges: coastline to deep sea. Aberdeen, Scotland, IEEE Ocean Engineering Society, pp 331-334. DOI: 10.1109/OCEANSE.2007.4302251.

Stehli F.G., McAlester A.L. and Helsley C.E. (1967) Taxonomic diversity of recent bivalves and some implications for geology. Geological Society of America Bulletin, 78, 455-466.

Ter Braak C.J.F. and Smilauer P. (1998) CANOCO reference manual and user's guide to Canoco for Windows: software for canonical community ordination (version 4). Microcomputer Power, Ithaca, NY USA, p. 352.

Willig M.R., Kaufman D.M. and Stevens R.D. (2003) Latitudinal gradients of biodiversity: pattern, process, scale, and synthesis. Annual Review of Ecology, Evolution, and Systematics, 34, 273-309.

Zettler M.L., Karlsson A., Kontula T.,Gruszka P., Laine A.O. Herkül K., Schiele K. S., Maximov A., Haldin J. (2014) Biodiversity gradient in the Baltic Sea: a comprehensive inventory of macrozoobenthos data. Helgoland Marine Research, 68, 1, 49-57. 
Table 1. Characteristics of the EMBOS soft substrate sample locations. Values of the Mud (\% DW; <63 $\mu$ m), Organic matter (\%) content of sediment, and Salinity are averages of measurements at each site according to the EMBOS protocol. Values for wave height ( $\mathrm{m}$ ) and sea surface temperature (SST; $\left.{ }^{\circ} \mathrm{C}\right)$ are the resultant of long-term Remote Sensing data interpretations for the coastal zone as specified in the Material \& Methods.

\begin{tabular}{|c|c|c|c|c|c|c|c|c|c|c|c|c|c|}
\hline Location & Region & $\begin{array}{l}\text { Subregion } \\
\text { (Med. = } \\
\text { Mediterranean) }\end{array}$ & $\begin{array}{l}\text { System } \\
\text { type }\end{array}$ & $\begin{array}{l}\text { Sample } \\
\text { date } \\
(2014)\end{array}$ & $\begin{array}{l}\text { Stratum } \\
\text { sampled }\end{array}$ & $\begin{array}{l}\text { Sampling } \\
\text { depth } \\
\text { (m, } \\
\text { relative } \\
\text { to LWL ) }\end{array}$ & $\begin{array}{l}\text { Lati- } \\
\text { tude }\end{array}$ & $\begin{array}{l}\text { Longi- } \\
\text { tude }\end{array}$ & $\begin{array}{l}\text { Avg. Sea } \\
\text { Surface } \\
\text { Tempe- } \\
\text { rature } \\
\left({ }^{\circ} \mathrm{C}\right)\end{array}$ & Salinity & $\begin{array}{l}\text { Mud } \\
\text { content } \\
(\%)\end{array}$ & $\begin{array}{l}\text { Organic } \\
\text { matter } \\
\text { content } \\
(\%)\end{array}$ & $\begin{array}{l}\text { Avg. } \\
\text { wave } \\
\text { height } \\
\text { (m) }\end{array}$ \\
\hline EE-Väike Väin Strait & Baltic & Baltic Sea & Open coast & $9 \mathrm{Apr}$ & Subtidal & -0.6 & 58.511 & 23.200 & 6.45 & 4.61 & & & 0.24 \\
\hline EE-Gulf of Riga & Baltic & Baltic Sea & Open coast & $9 \mathrm{Apr}$ & Subtidal & -0.6 & 58.371 & 22.982 & 7.67 & 5.04 & & & 0.64 \\
\hline LT-Curonian lagoon & Baltic & Baltic Sea & Lagoon & $20 \mathrm{Apr}$ & Subtidal & -0.8 & 55.373 & 21.213 & 8.96 & 0.20 & 2.88 & 0.84 & 0.63 \\
\hline PL-Puck bay & Baltic & Baltic Sea & Open coast & $7 \mathrm{Apr}$ & Subtidal & -0.5 & 54.454 & 18.566 & 7.74 & 8.00 & 0.19 & 0.14 & 0.38 \\
\hline PL-Vistula lagoon 1 & Baltic & Baltic Sea & Lagoon & $30 \mathrm{Apr}$ & Subtidal & -1.0 & 54.331 & 19.542 & 8.96 & 2.19 & 1.36 & 0.35 & 0.43 \\
\hline PL-Vistula lagoon 2 & Baltic & Baltic Sea & Lagoon & $30 \mathrm{Apr}$ & Subtidal & -1.0 & 54.331 & 19.470 & 8.92 & 2.07 & 2.12 & 0.39 & 0.43 \\
\hline NL-Oosterschelde & Atlantic & North Sea & Lagoon & $3 \mathrm{Apr}$ & Intertidal & +0.05 & 51.518 & 4.063 & 11.57 & 29.33 & 2.14 & 0.57 & 0.54 \\
\hline GB-Salcombe estuary & Atlantic & English Chan. & Estuary & $30 \mathrm{Apr}$ & Intertidal & +2.0 & 50.237 & -3.760 & 12.52 & 34.41 & 7.08 & 1.73 & 1.25 \\
\hline FR-Pertuis Charentais & Atlantic & Bay of Biscay & Open coast & $29 \mathrm{Apr}$ & Intertidal & +0.95 & 46.123 & -1.146 & 14.48 & 32.10 & 8.17 & 1.44 & 0.68 \\
\hline FR-Arcachon bay 1 & Atlantic & Bay of Biscay & Lagoon & $2 \mathrm{Apr}$ & Intertidal & +0.1 & 44.690 & -1.081 & 15.56 & 17.00 & 37.34 & 2.47 & 0.97 \\
\hline FR-Arcachon bay 2 & Atlantic & Bay of Biscay & Lagoon & $2 \mathrm{Apr}$ & Subtidal & -1.0 & 44.690 & -1.081 & 15.56 & 17.00 & 56.80 & 4.99 & 0.97 \\
\hline FR-Arcachon bay 3 & Atlantic & Bay of Biscay & Lagoon & $1 \mathrm{Apr}$ & Intertidal & +0.1 & 44.674 & -1.209 & 15.61 & 27.10 & 8.73 & 1.60 & 1.43 \\
\hline FR-Arcachon bay 4 & Atlantic & Bay of Biscay & Lagoon & $1 \mathrm{Apr}$ & Subtidal & -1.0 & 44.674 & -1.209 & 15.61 & 27.10 & 38.26 & 4.04 & 1.43 \\
\hline ES-Bay of Santander 1 & Atlantic & Bay of Biscay & Estuary & $15 \mathrm{Apr}$ & Intertidal & +0.5 & 43.438 & -3.788 & 15.99 & 34.00 & 10.37 & 1.45 & 1.30 \\
\hline ES-Bay of Santander 2 & Atlantic & Bay of Biscay & Estuary & $16 \mathrm{Apr}$ & Intertidal & +0.5 & 43.424 & -3.803 & 15.99 & 34.00 & 34.11 & 3.60 & 1.30 \\
\hline ES-Ria Vigo & Atlantic & Atlantic Ocean & Lagoon & $1 \mathrm{Apr}$ & Intertidal & +1.3 & 42.324 & -8.615 & 15.08 & 21.16 & 4.10 & 2.89 & 0.79 \\
\hline PT-Ria de Aveiro & Atlantic & Atlantic Ocean & Open coast & $25 \mathrm{Apr}$ & Intertidal & +1.0 & 40.860 & -8.656 & 15.63 & 12.58 & 4.05 & 1.07 & 1.27 \\
\hline PT-Sines beach & Atlantic & Atlantic Ocean & Open coast & $14 \mathrm{Apr}$ & Intertidal & +0.8 & 37.954 & -8.866 & 16.91 & 34.40 & 0.90 & 0.49 & 1.64 \\
\hline ES-Mar Menor - Encañizadas & Med. & Western Med. & Lagoon & $2 \mathrm{Apr}$ & Subtidal & -0.8 & 37.796 & -0.762 & 19.22 & 43.51 & 9.30 & 2.50 & 0.62 \\
\hline ES-Mar Menor - Los Urrutias & Med. & Western Med. & Lagoon & $2 \mathrm{Apr}$ & Subtidal & -1.0 & 37.687 & -0.831 & 19.21 & 44.77 & 3.46 & 1.14 & 0.61 \\
\hline IT-Oristano gulf - Marceddi & Med. & Western Med. & Open coast & $10 \mathrm{Apr}$ & Subtidal & -0.6 & 39.724 & 8.507 & 18.47 & 39.67 & 7.39 & 1.01 & 0.85 \\
\hline IT-Oristano gulf - Mistras & Med. & Western Med. & Lagoon & $14 \mathrm{Apr}$ & Subtidal & -0.6 & 39.892 & 8.449 & 18.43 & 41.63 & 7.39 & 1.01 & 0.85 \\
\hline GR-Amvrakikos Gulf 1 & Med. & Ionian Sea & Lagoon & $7 \mathrm{Apr}$ & Subtidal & -0.7 & 39.041 & 20.914 & 19.79 & 20.50 & 48.97 & 9.61 & 0.20 \\
\hline GR-Amvrakikos Gulf 2 & Med. & Ionian Sea & Lagoon & $7 \mathrm{Apr}$ & Subtidal & -1.0 & 39.036 & 20.879 & 19.78 & 22.80 & 24.37 & 2.89 & 0.20 \\
\hline GR-Crete - Balos 1 & Med. & Sea of Crete & Open coast & 28 May & Intertidal & +0.1 & 35.582 & 23.588 & 19.90 & 38.67 & 0.54 & 1.96 & 0.98 \\
\hline GR-Crete - Balos 2 & Med. & Sea of Crete & Open coast & 28 May & Subtidal & -0.3 & 35.583 & 23.591 & 19.90 & 39.17 & 0.96 & 1.78 & 0.98 \\
\hline CY-Softades - Larnaca 1 & Med. & Eastern Med. & Open coast & $8 \mathrm{Apr}$ & Subtidal & -1.0 & 34.813 & 33.541 & 21.46 & 39.26 & 1.93 & 1.35 & 0.35 \\
\hline CY-Softades - Larnaca 2 & Med. & Eastern Med. & Open coast & 1 May & Subtidal & -0.5 & 34.813 & 33.541 & 21.46 & 39.26 & 2.25 & 1.04 & 0.35 \\
\hline
\end{tabular}


Table 2: ANOSIM pairwise global tests on the differentiation between regions on basis of macrozoobenthic species and densities ( $2 a-$ for the regions: global $R=0.439$, significance level of sample statistic $0.1 \% ; 2 b-$ for the subregions: global $R=0.619$, significance level of sample statistic $0.1 \%$; $n . s .=$ not significant)

Table 2a.

\begin{tabular}{lccccc}
\hline Regions compared & $\mathrm{R}$ & $\begin{array}{c}\text { Significance } \\
\text { level } \%\end{array}$ & $\begin{array}{c}\text { Possible } \\
\text { permutations }\end{array}$ & $\begin{array}{c}\text { Actual } \\
\text { permutations }\end{array}$ & $\begin{array}{c}\text { Number }>= \\
\text { observed }\end{array}$ \\
Mediterranean, Baltic & 0.54 & 0.1 & Very large & 999 & 0 \\
Mediterranean, Atlantic & 0.322 & 0.1 & Very large & 999 & 0 \\
Baltic, Atlantic & 0.522 & 0.1 & Very large & 999 & 0
\end{tabular}

Table 2b.

Groups

Eastern Mediterranean, Baltic Sea $\mathrm{R}$
statistic
0.63

Possible Actual Number $>=$

Eastern Mediterranean, Bay of Biscay

0.63 level \% permutations permutations observed

Eastern Mediterranean, Western Mediterranean

0.909

0.2

33649

65780

999

0.879

0.1

6188

999

0.384

0.1

2002

999

0.487

0.9

56

999

Eastern Mediterranean, English Channel

0.753

3.6

462

0.628

Eastern Mediterranean, Sea of Crete

0.615

Eastern Mediterranean, North Sea

0.734

Baltic Sea, Western Mediterranean

0.659

0.378

Baltic Sea, Atlantic Ocean

0.555

Baltic Sea, Ionian Sea

0.607

0.595

Baltic Sea, Sea of Crete

0.341

Bay of Biscay, Western Mediterranean

0.61

Bay of Biscay, Atlantic Ocean

0.595

0.626

Bay of Biscay, English Channel

0.638

Bay of Biscay, Ionian Sea

0.802

Bay of Biscay, Sea of Crete

Bay of Biscay, North Sea

Western Mediterranean, Atlantic Ocean

0.492

0.523

Western Mediterranean, English Channel

0.827

Western Mediterranean, Ionian Sea

0.405

Western Mediterranean, Sea of Crete

0.686

Western Mediterranean, North Sea

0.816

Atlantic Ocean, English Channel

0.067

Atlantic Ocean, Ionian Sea

Atlantic Ocean, Sea of Crete

Atlantic Ocean, North Sea

English Channel, Ionian Sea

English Channel, Sea of Crete

English Channel, North Sea

0.361

0.373

0.2

462

0.2

56

0.1

very large

86493225

4686825

1330

134596

134596

1330

56

462

462

\section{6}

999

999

999

999

999

999

999

354817320

999

999

999

999

999

999

999

455

999

999

455

220

999

0.056

1

0.691

0.926

Ionian Sea, Sea of Crete

Ionian Sea, North Sea

0.756

26.8 (n.s)

0.5

220

5005

0.6

5005

999

220

32.7 (n.s)

220

1.2

1.2

10.0 (n.s)

0.2

1

Sea of Crete, North Sea

0.66

1.2

1.2

84

84

10

462

84

84

84

84

10

462

84

84

1

0

0

8

2

1

1

1

0

0

0


Table 3. Results of Principal Component Analysis (PCA) between the diversity and density based macrozoobenthic community descriptors (number of species (S), total density (n), Margalef species richness (d), Pielou evenness $\left(\mathrm{J}^{\prime}\right)$ and Shannon diversity $\left(\mathrm{H}^{\prime}\right)$ per sample) and environmental and geographic location characteristics (characteristics with little explanatory power towards the observed patterns in species compositions are not indicated; to these belong the environmental variables 'CaCO3 content' and 'sampling depth').

\begin{tabular}{|c|c|c|}
\hline & Axis 1 & Axis 2 \\
\hline \multicolumn{3}{|c|}{ Summary statistics of first two canonical axes } \\
\hline Eigenvalues & 0.908 & 0.082 \\
\hline Species-environment correlations & 0.842 & 0.839 \\
\hline \multicolumn{3}{|l|}{ Cumulative percentage variance } \\
\hline of species data & 90.8 & 99.0 \\
\hline of species-environment relation & 91.4 & 99.6 \\
\hline \multicolumn{3}{|c|}{ Correlation of geographic variables with canonical axes } \\
\hline Baltic & 0.0188 & 0.6670 \\
\hline Atlantic & -0.1883 & -0.4315 \\
\hline Latitude & -0.1273 & 0.4246 \\
\hline Longitude & 0.3837 & 0.3715 \\
\hline \multicolumn{3}{|c|}{$\begin{array}{l}\text { Correlation of environmental variables and location } \\
\text { characteristics with canonical axes }\end{array}$} \\
\hline Salinity & -0.0314 & -0.6280 \\
\hline Temperature & 0.0988 & -0.4795 \\
\hline Wave height & -0.1934 & -0.4638 \\
\hline Mud content (\%) & -0.3194 & -0.3436 \\
\hline Organic matter content (\%) & -0.3341 & -0.3063 \\
\hline Lagoon & -0.4449 & -0.0325 \\
\hline Open coast & 0.5080 & 0.2662 \\
\hline Estuary & -0.0913 & -0.3611 \\
\hline Intertidal & 0.0023 & -0.3658 \\
\hline
\end{tabular}




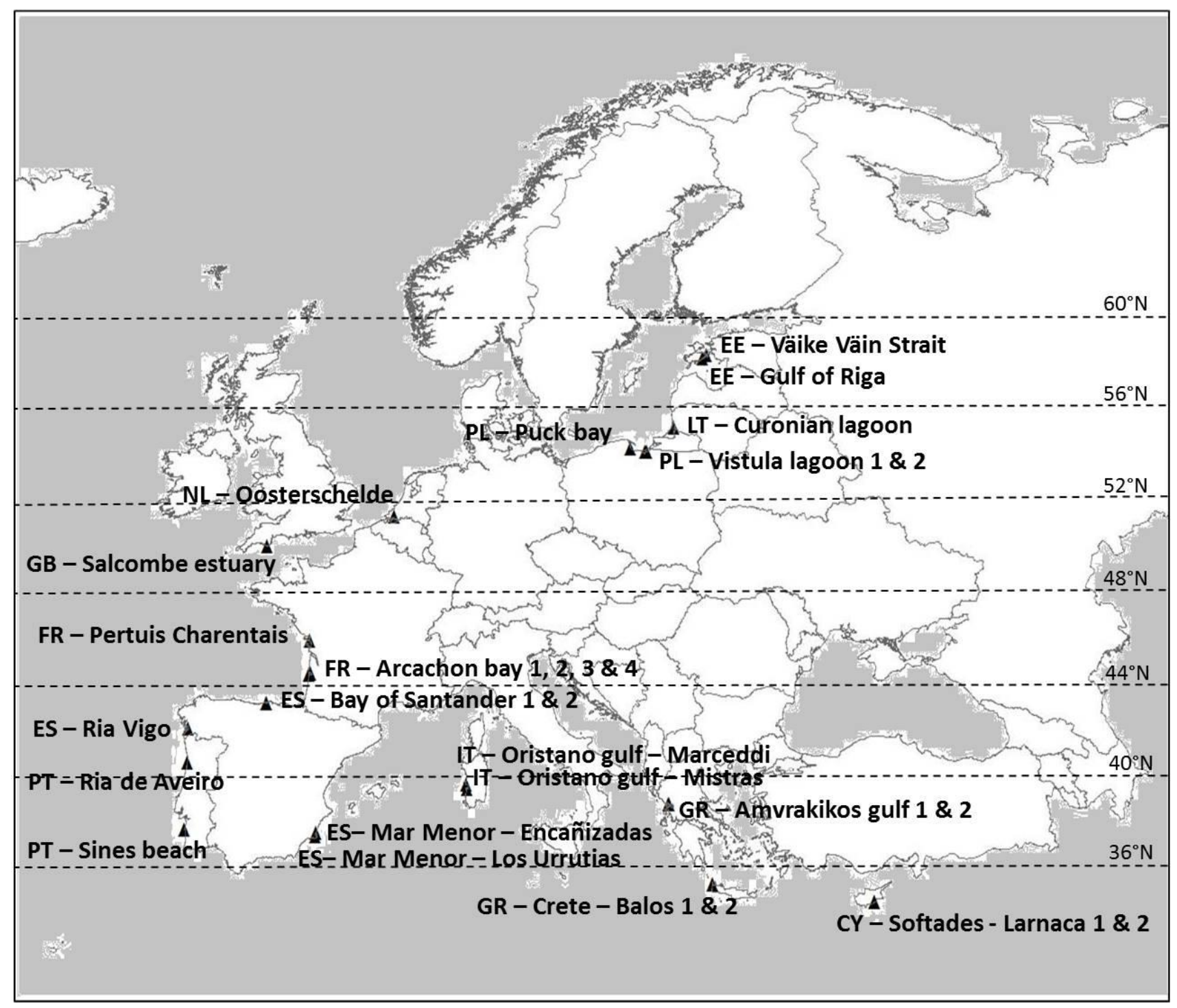

Fig. 1. EMBOS soft substrate sampling locations 


\section{Sampling Plot X.1 \\ 3 replicates \\ core $\varnothing 13 \mathrm{~cm}$ \\ $0.5 \mathrm{~mm}$ sieve}

Station X

1 series of 3 plots above LWL

1 series of 3 plots in upper subtidal

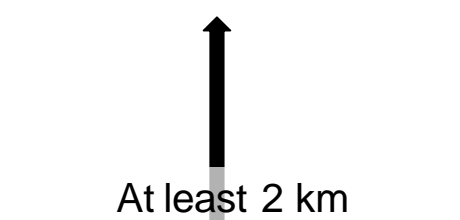

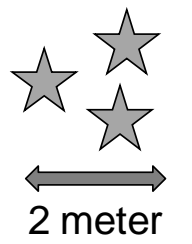

Sampling Plot X.2

3 replicates core $\varnothing 13 \mathrm{~cm}$

$0.5 \mathrm{~mm}$ sieve

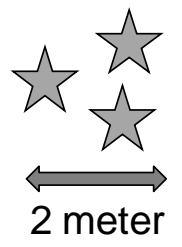

Sampling Plot X.3

3 replicates core $\varnothing 13 \mathrm{~cm}$

$0.5 \mathrm{~mm}$ sieve

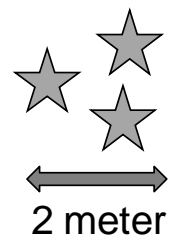

\section{0 to 200 meter}

\section{Sampling Plot Y.2}

3 replicates

core $\varnothing 13 \mathrm{~cm}$

$0.5 \mathrm{~mm}$ sieve

core $\varnothing 13 \mathrm{~cm}$

$0.5 \mathrm{~mm}$ sieve

\section{Station $Y$}

1 series of 3 plots above LWL 1 series of 3 plots in upper subtidal

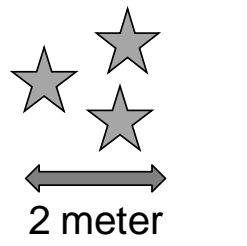

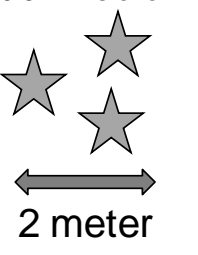

Sampling Plot Y.3

3 replicates core ø $13 \mathrm{~cm}$ $0.5 \mathrm{~mm}$ sieve

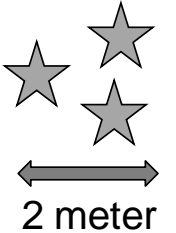

100 to 200 meter

Fig. 2. Harmonised EMBOS sampling scheme

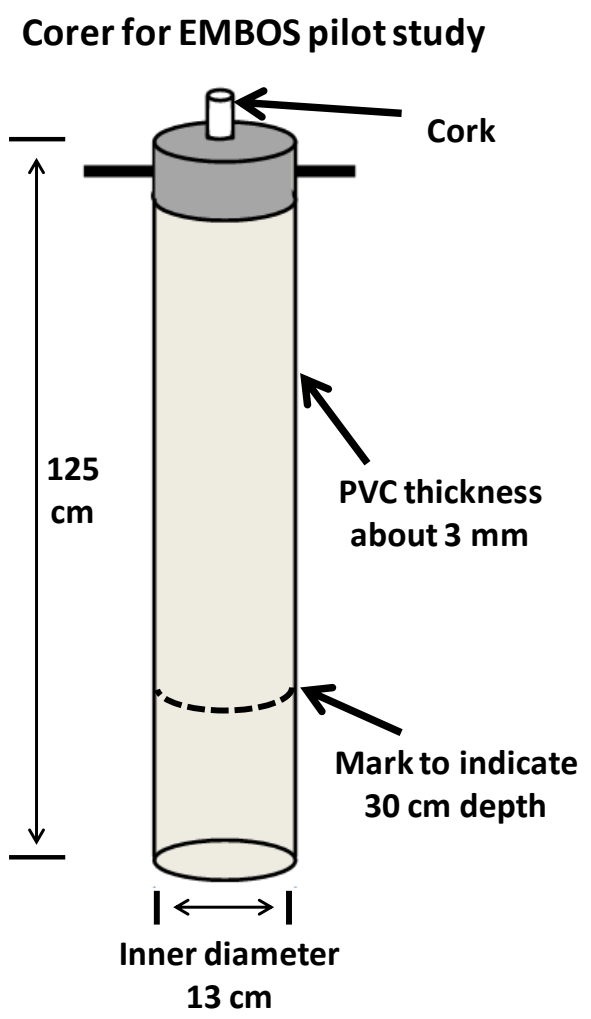

Fig. 3. Standard EMBOS sampling corer for soft sediments 


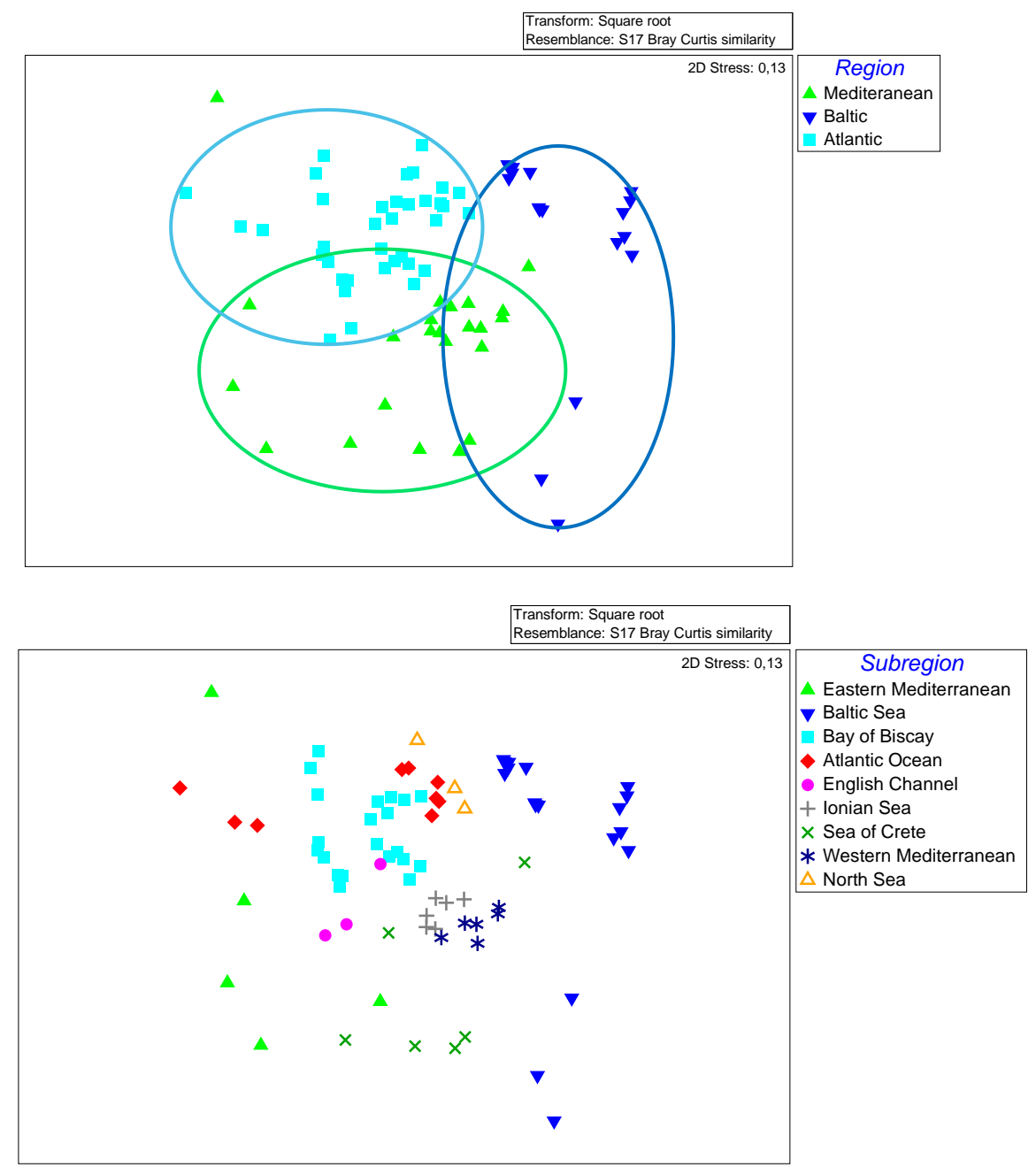

Fig. 4. MDS analysis of the on densities based macrozoobenthos species compositions for the major European regions (a) and their subregions (b).
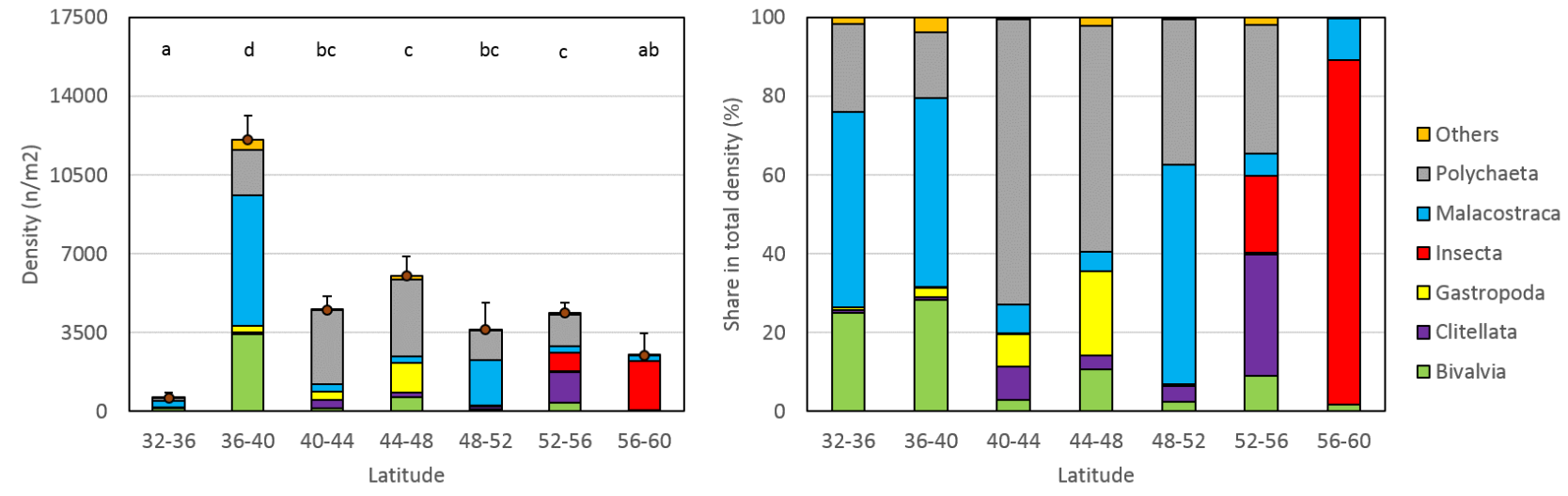

Fig. 5. Absolute (a) and relative (b) numbers of individuals per major taxonomic group with latitude. Average total densities \pm standard error for clusters in steps of $4^{\circ}$ latitude; significant differences in total densities are indicated with different characters. 

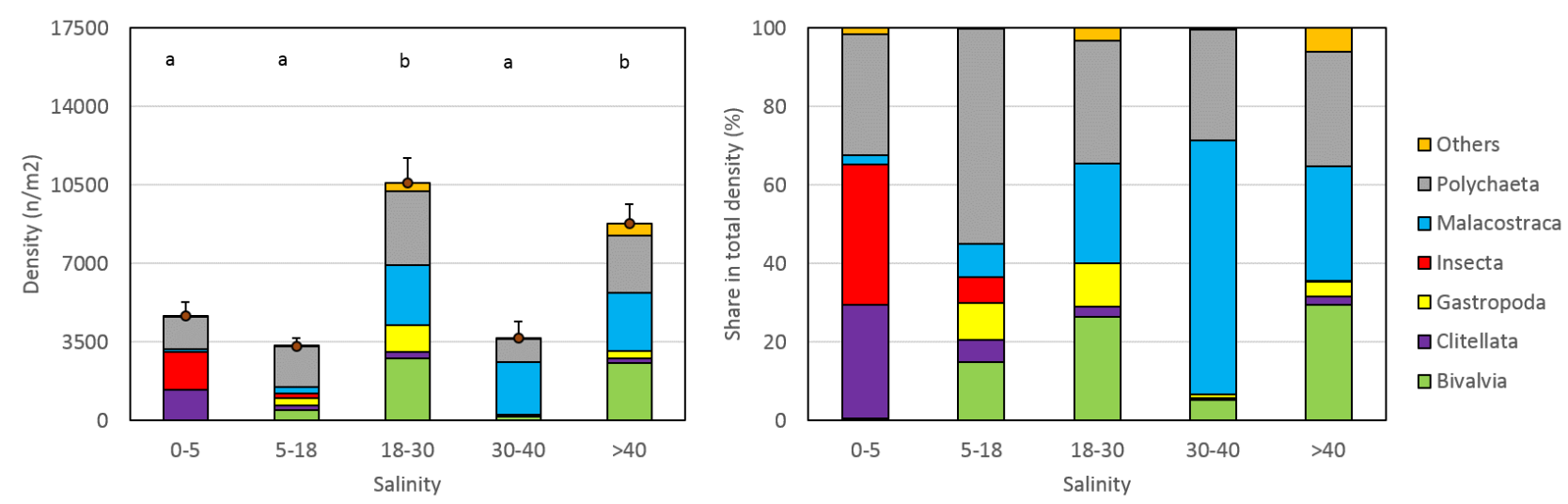

Fig. 6. Absolute (a) and relative (b) numbers of individuals per major taxonomic group with salinity. Average total densities \pm standard error for clusters according to the Thalassic salinity series $(0-5=$ oligohaline, 5-18 = mesohaline, $18-30=$ polyhaline, $30-40=$ mixoeuhaline, $>40=$ metahaline); significant differences in total densities are indicated with different characters.
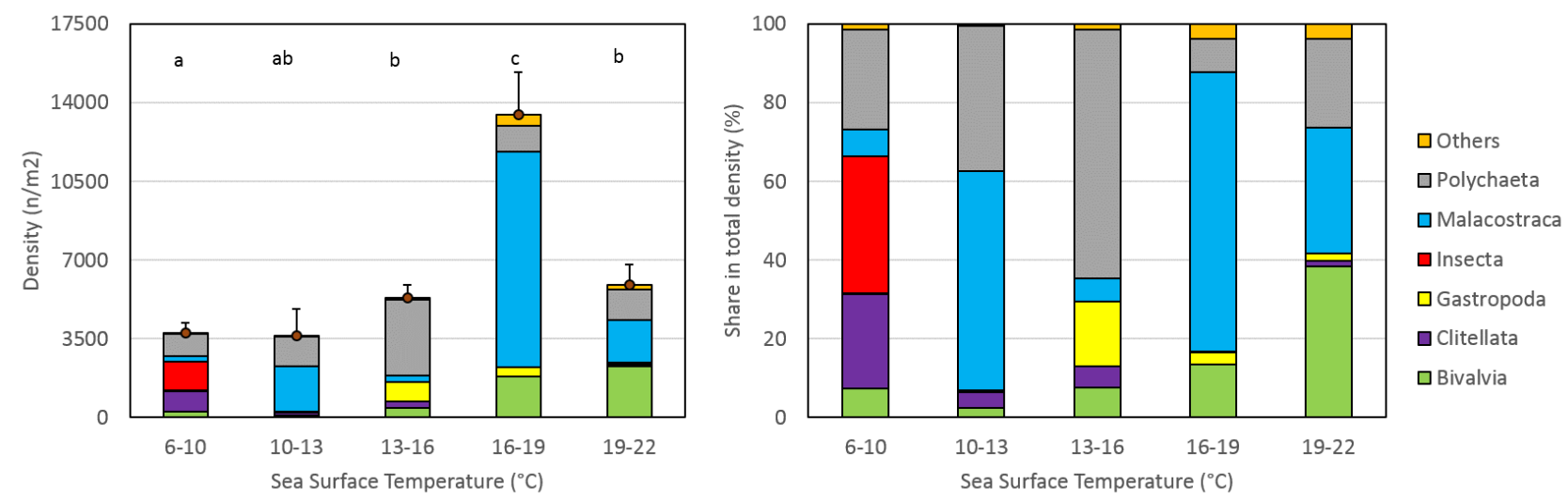

Fig. 7. Absolute (a) and relative (b) numbers of individuals per major taxonomic group with year average sea surface temperature $\left({ }^{\circ} \mathrm{C}\right)$. Average total densities \pm standard error for clusters in steps of $4{ }^{\circ} \mathrm{C}$, except for the lowest temperature class that covers $5{ }^{\circ} \mathrm{C}$; significant differences in total densities are indicated with different characters. 


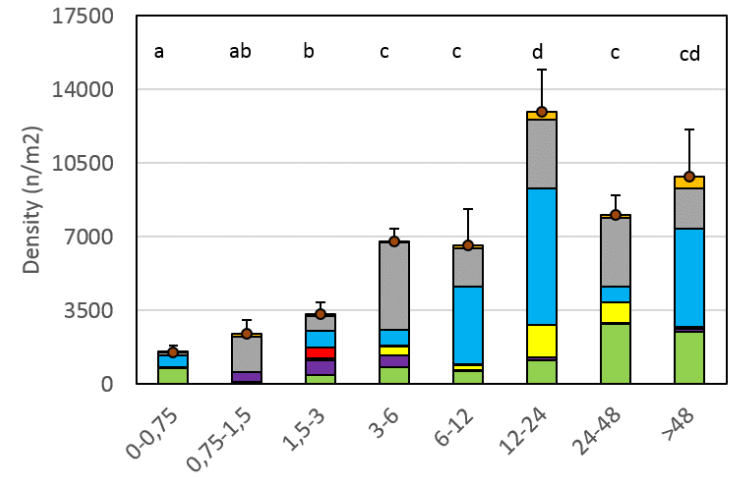

Mud content (\%)

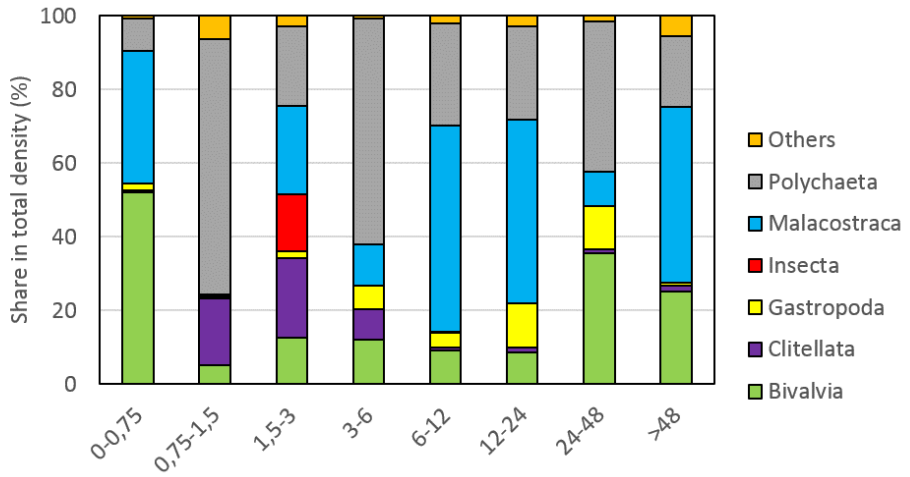

Mud content (\%)

Fig. 8. Absolute (a) and relative (b) numbers of individuals per major taxonomic group with mud (<63 $\mu \mathrm{m})$ content (\%). Average total densities \pm standard error for clusters of times 2 increasing mud contents; significant differences in total densities are indicated with different characters.
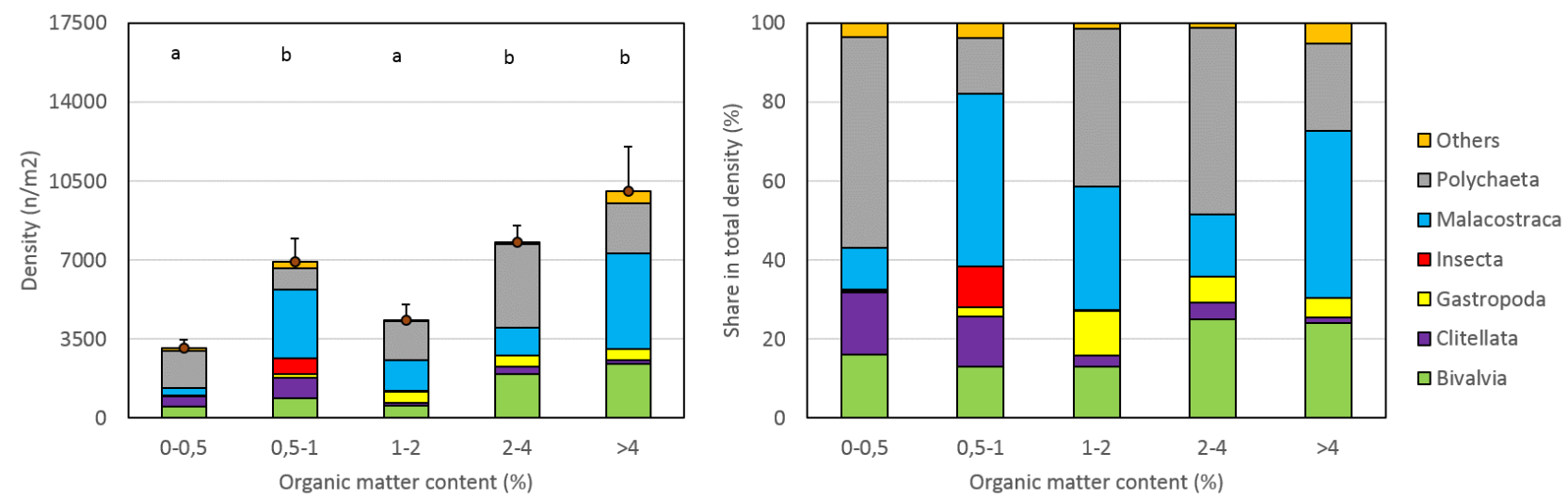

Fig. 9. Absolute (a) and relative (b) numbers of individuals per major taxonomic group with organic matter content (\% DW). Average total densities \pm standard error for clusters of times 2 increasing organic matter contents; significant differences in total densities are indicated with different characters. 

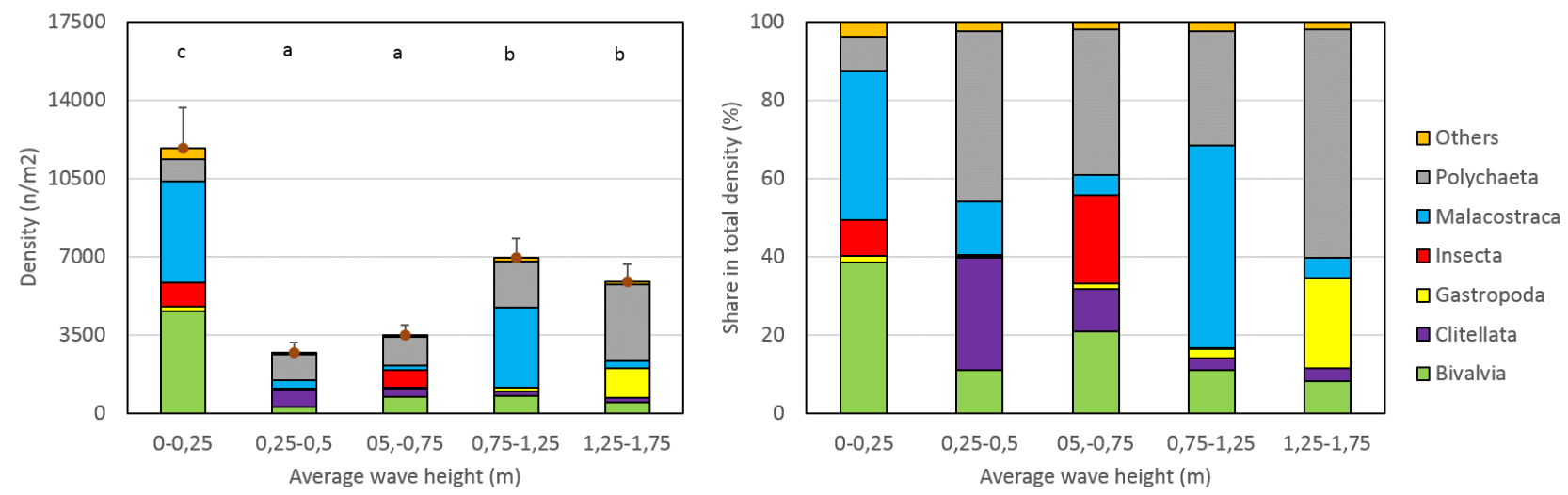

Fig. 10. Absolute (a) and relative (b) numbers of individuals per major taxonomic group with average wave height $(m)$. Average total densities \pm standard error for clusters of increasing wave height; significant differences in total densities are indicated with different characters.
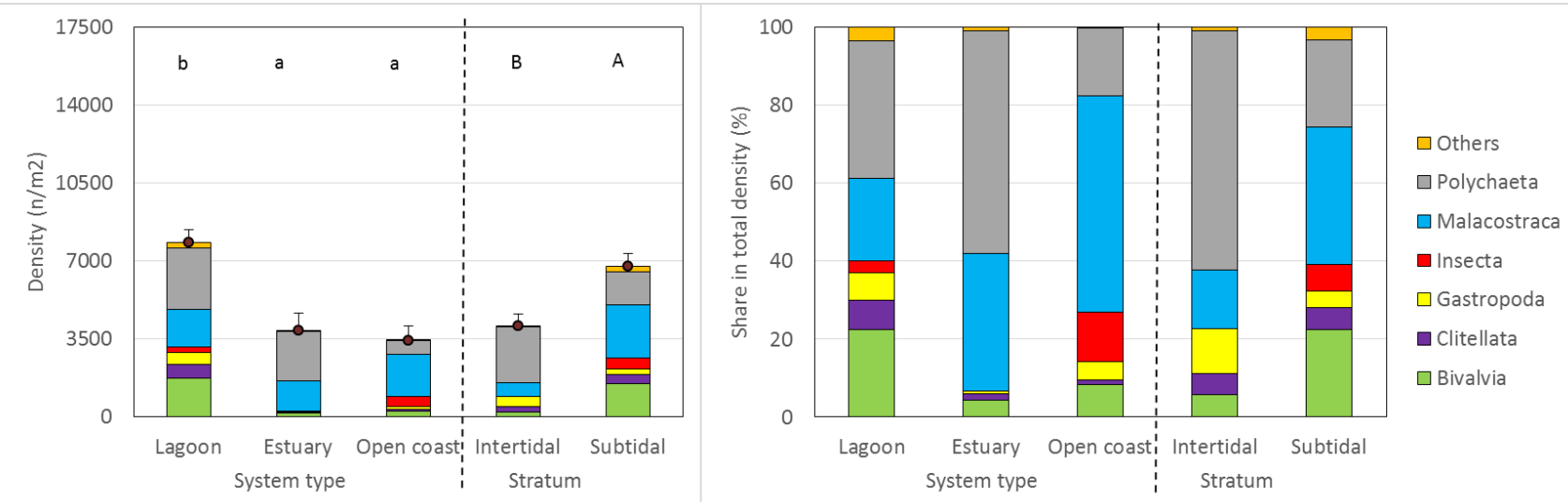

Fig. 11. Absolute (a) and relative (b) numbers of individuals per major taxonomic group for each of the identified system types and strata where sampling has taken place. Average total densities \pm standard error; significant differences in total densities are indicated with different characters where both classification systems (types and strata) have been tested separately as they consist of the same samples. 


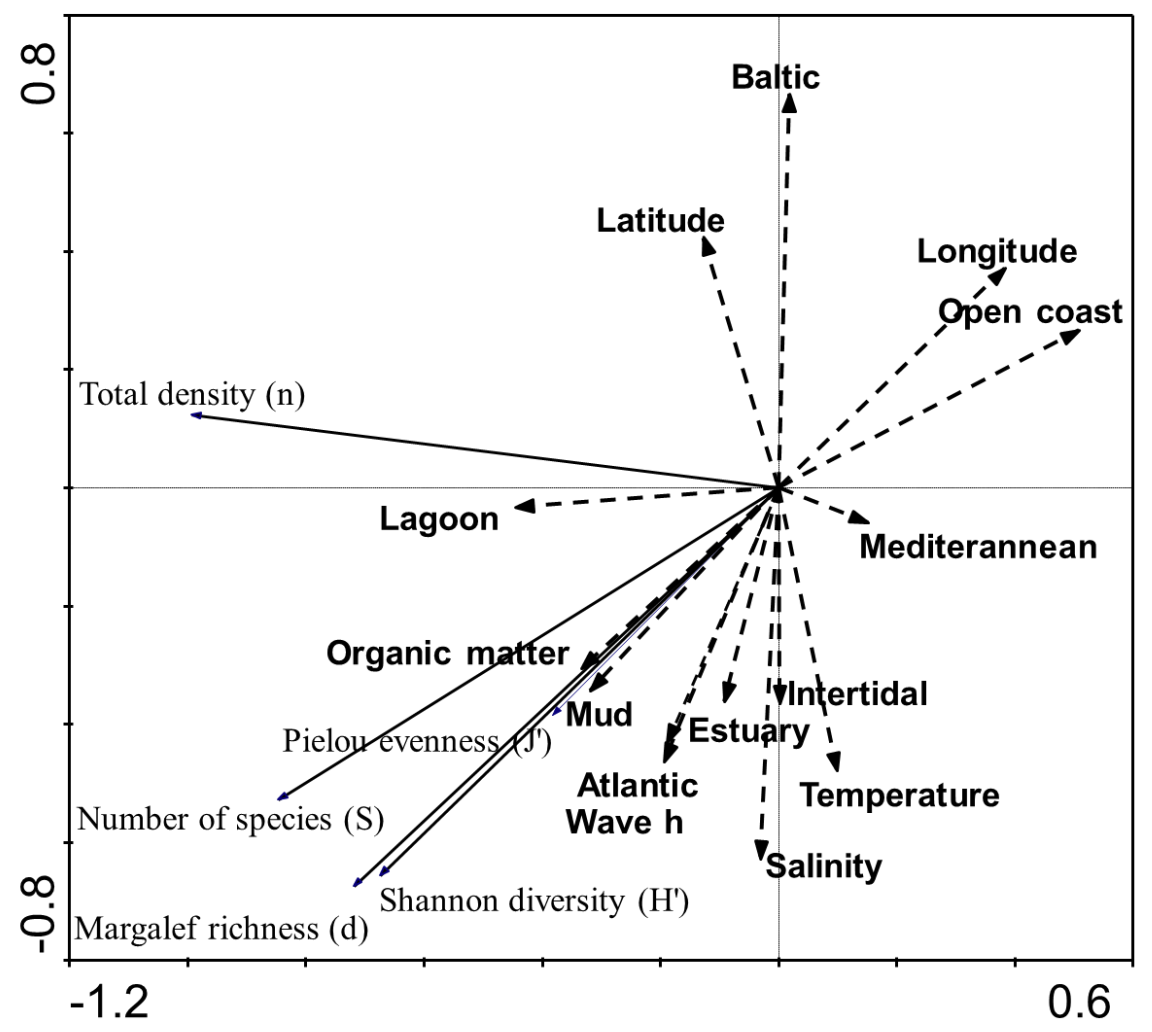

Fig. 12. Results of a Principal Component Analysis (PCA) based on macrozoobenthic community descriptors (diversity and densities descriptors). Most important correlated environmental (continuous variables) and geographic (presence/absence data) characteristics are plotted as dashed vectors afterwards (as a PCA is an indirect gradient analysis) (Wave $\mathrm{h}=$ wave height).

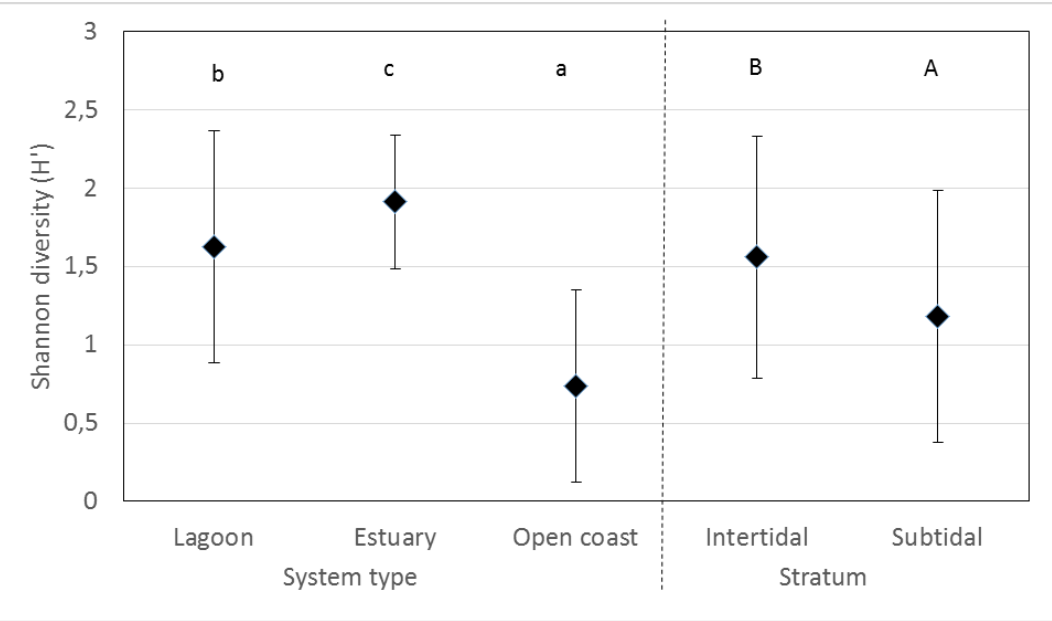

Fig. 13. Shannon diversity (average \pm standard deviation) of macrozoobenthos.for each of the identified system types and strata where sampling has taken place. Significant differences in Shannon diversity are indicated with different characters; both classification systems (types and strata) have been tested separately as they consist of the same samples. 

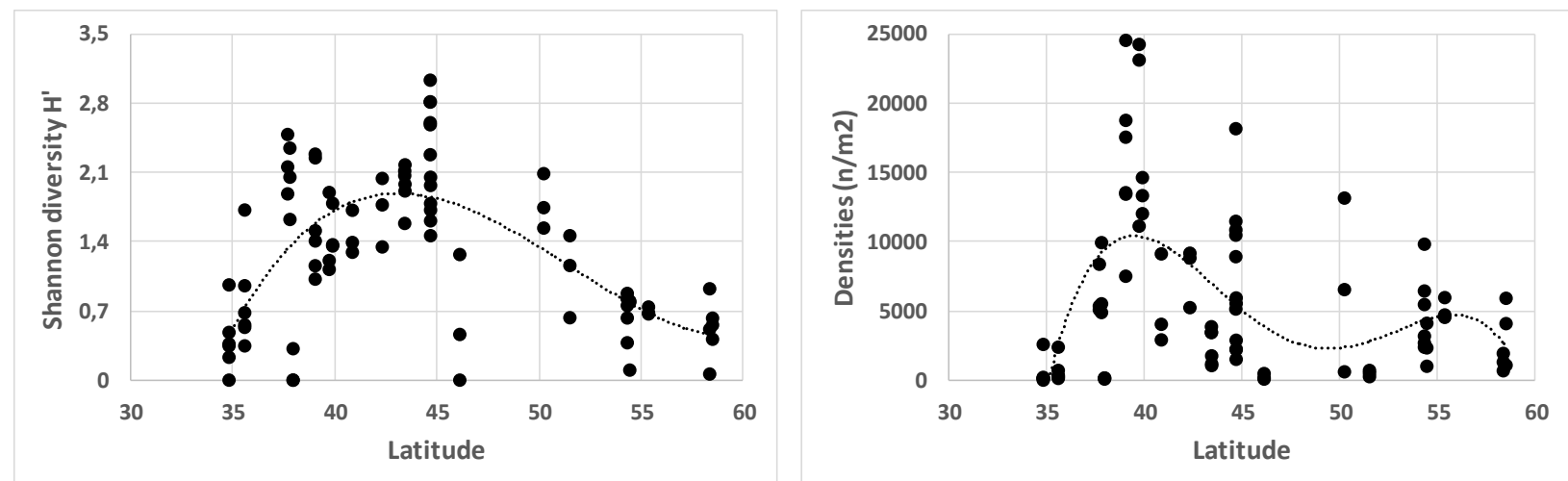

Fig. 14. Diversity ( $a$; Shannon $\mathrm{H}^{\prime} ; 3^{\text {rd }}$ order polynomial, $\mathrm{r}^{2}=0.48, \mathrm{p}<0.001$ ) and density ( $b$; total number per $\mathrm{m}^{2} ; 4^{\text {th }}$ order polynomial, $\mathrm{r}^{2}=0.34, \mathrm{p}<0.001$ ) of macrozoobenthos with latitude.
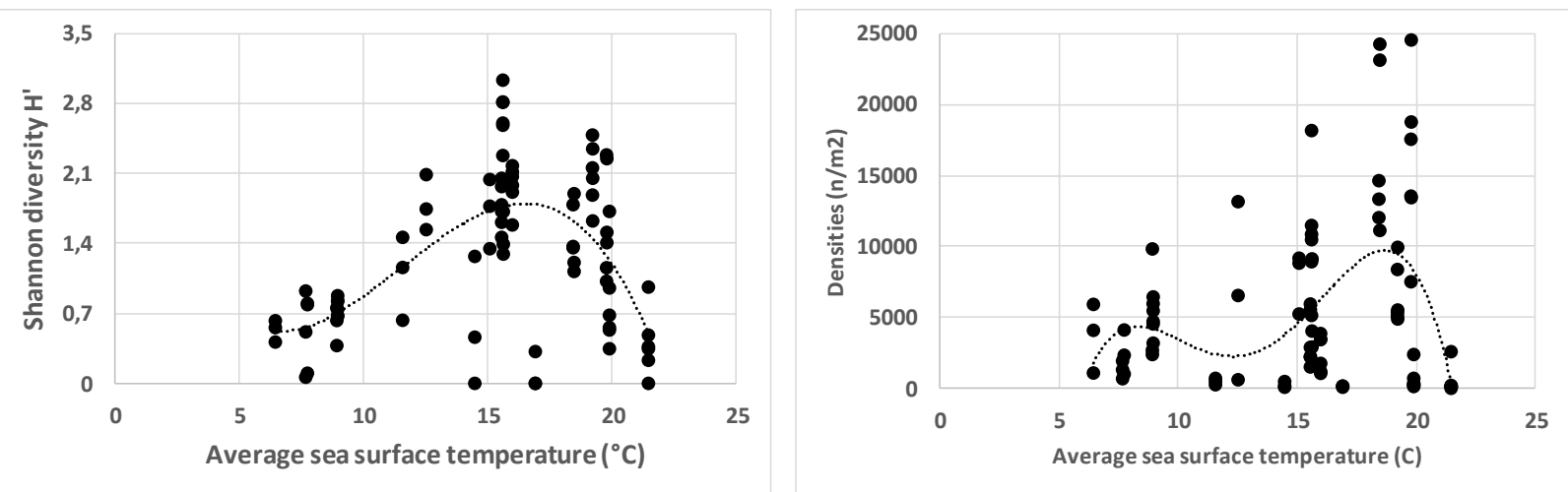

Fig. 15. Diversity (a; Shannon $\mathrm{H}^{\prime} ; 3^{\text {rd }}$ order polynomial, $\left.\mathrm{r}^{2}=0.39, \mathrm{p}<0.001\right)$ and density $(b$; total number per $\mathrm{m}^{2} ; 4^{\text {th }}$ order polynomial, $\left.\mathrm{r}^{2}=0.21, \mathrm{p}<0.001\right)$ of macrozoobenthos with sea surface temperature (SST, ${ }^{\circ} \mathrm{C}$ ).
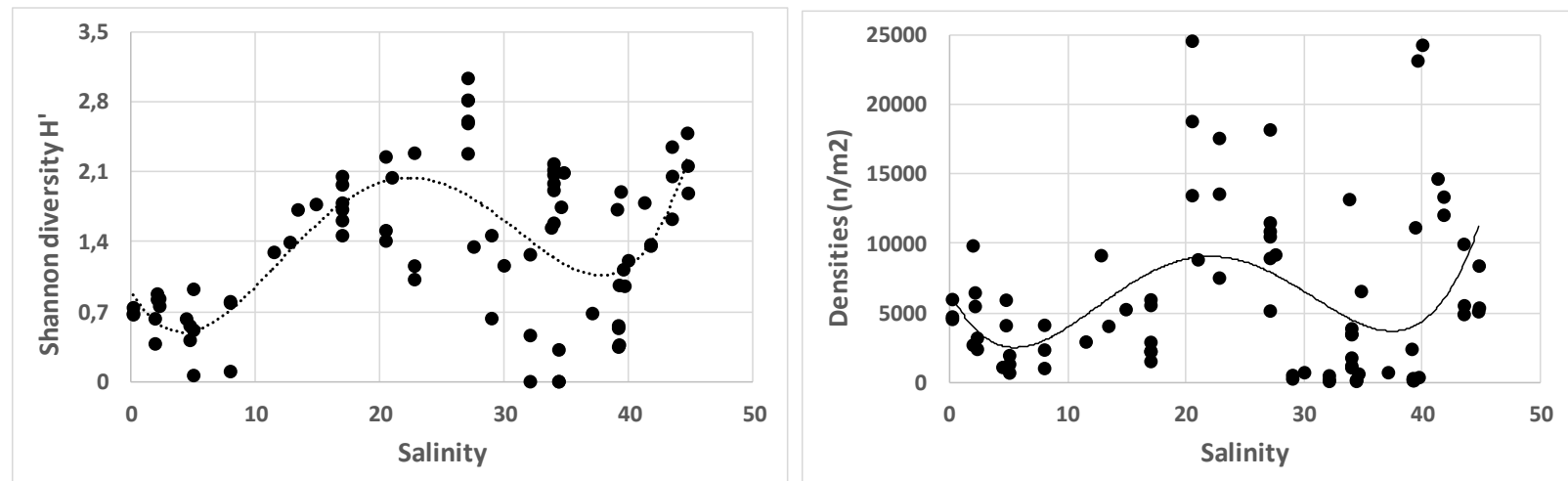

Fig. 16. Diversity ( $a$; Shannon $\mathrm{H}^{\prime} ; 4^{\text {th }}$ order polynomial, $\mathrm{r}^{2}=0.44, \mathrm{p}<0.001$ ) and density ( $b$; total number per $\mathrm{m}^{2} ; 4^{\text {th }}$ order polynomial, $\left.\mathrm{r}^{2}=0.16, \mathrm{p}<0.01\right)$ of macrozoobenthos with salinity. 

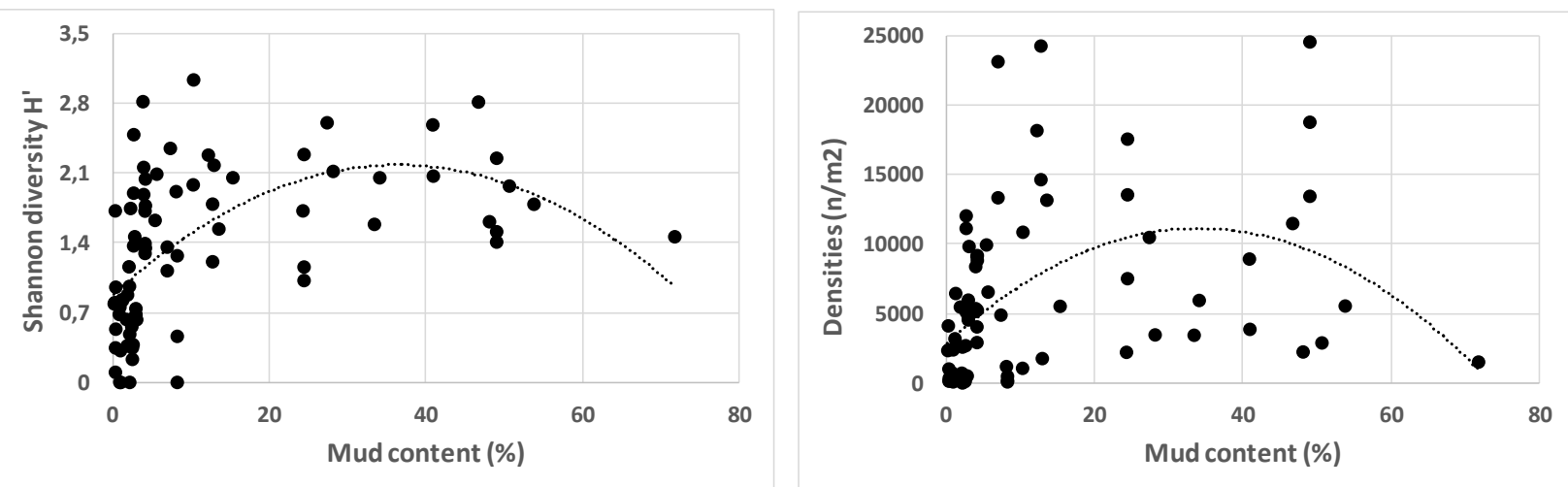

Fig. 17. Diversity ( $a$; Shannon $\mathrm{H}^{\prime} ; 2^{\text {nd }}$ order polynomial, $\left.\mathrm{r}^{2}=0.32, \mathrm{p}<0.001\right)$ and density $(b ;$ total number per $\mathrm{m}^{2}, 2^{\text {nd }}$ order polynomial. $\left.\mathrm{r}^{2}=0.20, p<0.001\right)$ of macrozoobenthos with mud content (\%DW).
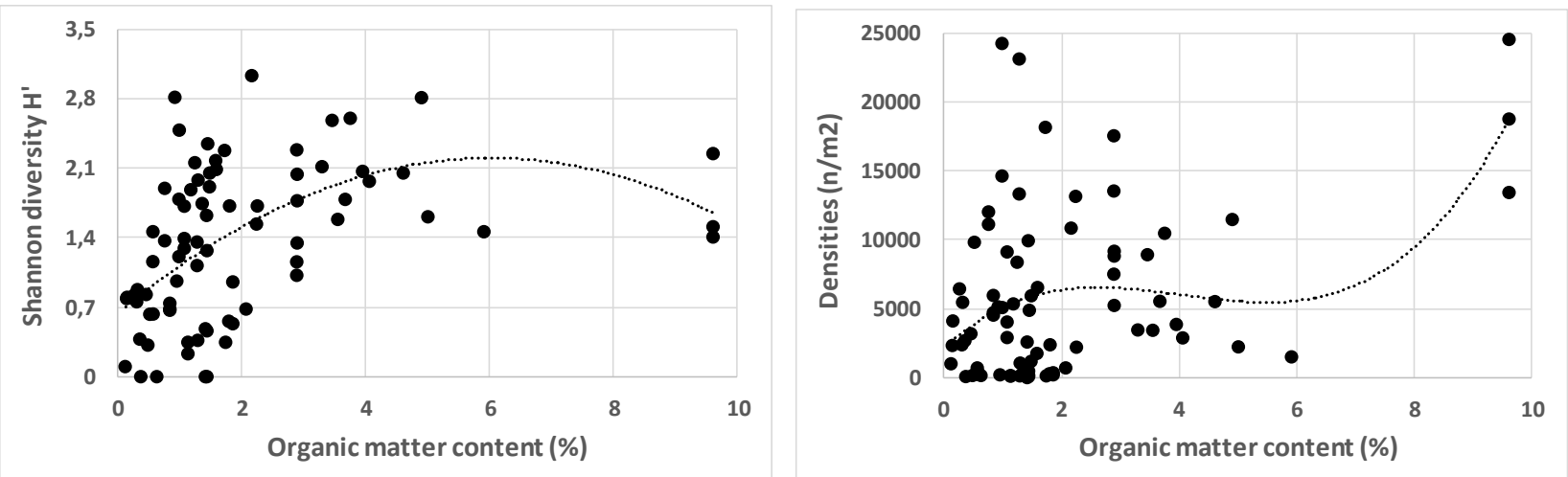

Fig. 18. Diversity ( $a$; Shannon $\mathrm{H}^{\prime} ; 2^{\text {nd }}$ order polynomial, $\mathrm{r}^{2}=0.26, \mathrm{p}<0.001$ ) and density $(b ;$ total number per $\mathrm{m}^{2}, 3^{\text {rd }}$ order polynomial. $\left.\mathrm{r}^{2}=0.21, \mathrm{p}<0.001\right)$ of macrozoobenthos with organic matter content $(\% \mathrm{DW})$.
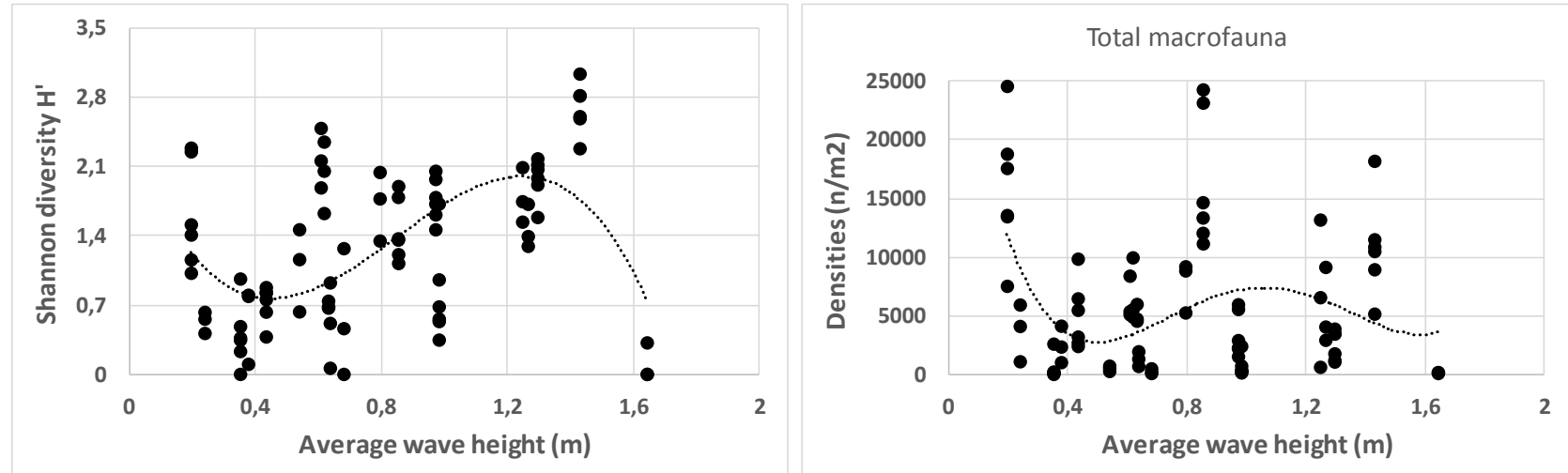

Fig. 19. Diversity ( $a$; Shannon $\mathrm{H}^{\prime} ; 3^{\text {rd }}$ order polynomial, $\mathrm{r}^{2}=0.41, \mathrm{p}<0.001$ ) and density ( $b$; total number per $\mathrm{m}^{2}, 4^{\text {th }}$ order polynomial. $\left.\mathrm{r}^{2}=0.37, \mathrm{p}<0.001\right)$ of macrozoobenthos with average wave height $(\% \mathrm{DW})$. 